NASA Technical Memorandum 101996

AIAA-89-1143

\title{
Noise of a Model Counterrotation Propeller With Simulated Fuselage and Support Pylon at Takeoff/Approach Conditions
}

Richard P. Woodward and Christopher E. Hughes

Lewis Research Center

Cleveland, Ohio

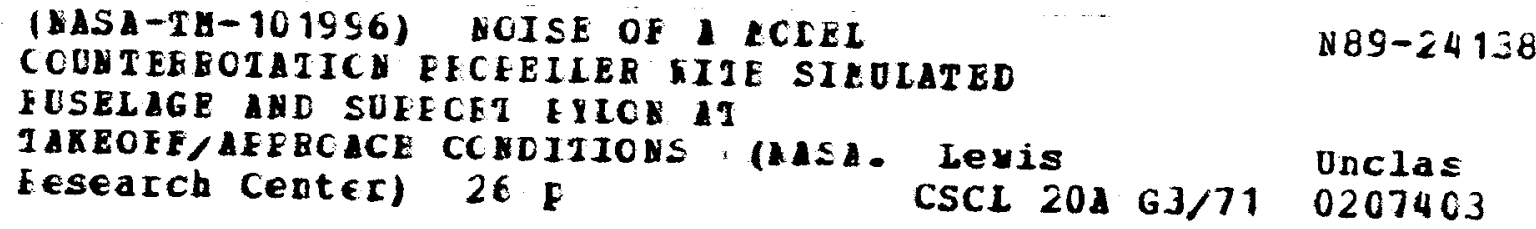

Prepared for the

12th Aeroacoustics Conference sponsored by the American Institute of Aeronautics and Astronautics San Antonio, Texas, April 10-12, 1989

\section{Nhs}


NOISE OF A MODEL COUNTERROTATION PROPELLER WITH SIMULATED FUSELAGE AND SUPPORT PYLON AT TAKEOFF/APPROACH CONDITIONS

Richard P. Woodward and Christopher E. Hughes

National Aeronautics and Space Administration

Lewis Research Center

Cleveland, Ohio 44135

\section{SUMMARY}

Two modern high-speed advanced counterrotation propellers, F7/A7 and F7/A3 were tested in the NASA Lewis Research Center's 9- by 15-Foot Anechoic Wind Tunnel at simulated takeoff/approach conditions of 0.2 Mach number. Both rotors were of similar diameter on the F7/A7 propeller, while the aft diameter of the F7/A3 propeller was 85 percent of the forward propeller to reduce tip vortex-aft rotor interaction. The two propellers were designed for similar performance. The propellers were tested in both the "clean" configuration, and "installed" configuration consisting of a simulated upstream nacelle support pylon and fuselage section. Acoustic measurements were made with an axially translating microphone probe, and with a "polar" microphone probe which was fixed to the propeller nacelle and could make both sideline and circumferential acoustic surveys. Aerodynamic measurements were also made to establish propeller operating conditions. The propellers were run at blade setting angles (front angle/rear angle) of $41.1^{\circ} / 39.4^{\circ}$ for the F7/A7 prope 1ler, and $41.1^{\circ} / 46.4^{\circ}$ for the F7/A3 propeller. The forward rotors were tested over a range of tip speeds from 165 to $259 \mathrm{~m} / \mathrm{sec}$ ( 540 to $850 \mathrm{ft} . / \mathrm{sec}$ ), and both propellers were tested at the maximum rotor-rotor spacing, based on pitch change axis separation, of $14.99 \mathrm{~cm}(5.90 \mathrm{in.})$. The data presented in this paper are for $0^{\circ}$ propeller axis angle of attack. Results are presented for the baseline, pylon-alone, and strut + fuselage configurations. The presence of the simulated fuselage resulted in higher rotor-alone tone levels in a direction normal to the advancing propeller blade near the fuselage. A corresponding rotor-alone tone reduction was often observed $180^{\circ}$ circumferentially from this region of increased noise. A significant rotor-alone increase for both rotors was observed diametrically opposite the fuselage. In some cases, interaction tone levels were likewise affected by the simulated installation.

\section{INTRODUCTION}

Modern high-performance turboprop aircraft offer the promise of considerable fuel savings while still allowing for a cruise speed similar to that of current turbofan aircraft. Advanced counterrotation propellers may offer from 8 to 10 percent additional fuel savings over similar single rotation propellers at cruise conditions (ref. 1). However, there is considerable concern about the potential noise generated by such aircraft, which includes both in-flight cabin noise and community noise during takeoff and landing.

This paper presents the acoustic results for a model counterrotation propeller which was tested in the NASA Lewis 9- by 15-Foot Anechoic Wind Tunnel. The test results are for 0.20 axial Mach number, which is representative of takeoff/approach operation. Acoustic test results are presented for two model

Copyright (C) 1989 by the American Institute of Aeronautics and Astronautics, Inc. No copyright is asserted in the

United States under Title 17, U.S. Code. The U.S. Government has a royalty-free license to exercise all rights under the copyright claimed herein for Governmental purposes.

All other rights are reserved by the copyright owner. 
propellers in the baseline or "clean" configuration, and for a simulated pusher installation consisting of a simulated upstream support pylon and fuselage section. The two test propellers (designated F7/A7 and F7/A3) both had 11 forward and 9 aft blades. Both rotors of the F7/A7 propeller were of essentially the same diameter; while the aft rotor diameter of the F7/A3 propeller was 85 percent of the forward diameter to reduce interaction tone levels resulting from the upstream rotor tip vortex interacting with the downstream rotor (refs. 2 to 4 ). The F7 upstream rotor was common to both propellers.

The two propellers were operated at blade setting angles which gave similar aerodynamic performance for the propellers. These angles were (front rotor/aft rotor) $41.1^{\circ} / 39.4^{\circ}$ for the F7/A7 propeller, and $41.1 / 46.4$ for the F7/A3 propeller. These blade setting angles resulted in a nearly equal forward/aft torque split between the two rotors of each propeller. Both propellers were operated at the "maximum" spacing between forward and aft rotor pitch changes axis of $14.99 \mathrm{~cm}(5.90 \mathrm{in.})$. The upstream pylon (when installed) axial distance to the forward rotor was the same for all tests. Results presented in this paper are for $0^{\circ}$ propeller axis angle-of-attack. Acoustic data were taken with a track microphone probe which was fixed to the tunnel floor, and with a "polar" microphone probe which was mounted on the downstream end of the propeller housing. The polar probe assembly surveyed both the angular and sideline noise fields. The unequal blade numbers of the $11 / 9$ configurations of the two propellers greatly simplified the acoustic analysis of the complicated counterrotation propeller spectra. Corresponding aerodynamic results are presented to establish the propeller operating conditions.

\section{APPARATUS AND PROCEDURE}

The NASA Lewis 9- by 15-Foot Anechoic Wind Tunnel is located in the low-speed return leg of the supersonic 8 - by 6-Foot Wind Tunnel. The maximum axial airflow velocity in the tunnel is slightly over 0.2 Mach, which provides a takeofflapproach test environment. The tunnel acoustic treatment was modified to provide anechoic conditions down to a frequency of $250 \mathrm{~Hz}$, which is well below the range of the fundamental tone produced by the model propellers.

Acoustic instrumentation in the 9- by 15-Foot Anechoic Wind Tunnel consisted of two remote-controlled acoustic probes, a "track" probe and a "polar" probe. The probes were instrumented with $0.64 \mathrm{~cm}(0.25 \mathrm{in.})$ condenser microphones. Two microphones were mounted on the track probe which was $f i x e d$ to the tunnel floor, and one similar microphone was mounted on the polar probe which was attached to the aft propeller housing. Figure 1 shows the model propeller and acoustic instrumentation installed in the anechoic wind tunnel. The simulated pusher nacelle support pylon and fuselage section are also in place. The polar microphone assembly is installed on the downstream end of the propeller housing, and a small section of the track microphone is visible in the lower right corner of the photograph. The track translating microphone probe traversed $6.50 \mathrm{~m}(21.33 \mathrm{ft}$.$) , which covered most of the 8.2 \mathrm{~m}(27 \mathrm{ft}$. length of the treated test section. The track probe data presented in this paper are for the inner microphone, which was located $137 \mathrm{~cm}$ (54 in.) from the propeller axis for $0^{\circ}$ angle of attack. This inner microphone for the track probe surveyed sideline angles from 18 to $150^{\circ}$ relative to the aft rotor axis of rotation at $0^{\circ}$ angle of attack. 
The polar microphone probe had the capability to survey much of the propeller noise field. As shown in the sketch of figure 2, the polar microphone probe was mounted on the downstream propeller housing and moved with the propeller at angles of attack (results for this paper are for $0^{\circ}$ angle of attack). The probe could perform sideline acoustic surveys extending about $45^{\circ}$ fore and aft of the aft propeller plane. Circumferential surveys could be made over a $240^{\circ}$ range, being limited by support hardware interference. The polar microphone was located $61 \mathrm{~cm}$ (24 in.) from the propeller axis of rotation.

Figure 2 also shows how the simulated pylon and fuselage was installed on the test apparatus. Steel beams supported the fuselage and pylon from the base of the model pedestal. The F7/A3 propeller was tested with the pylon alone, as well as with the pylon + fuselage; the F7/A7 propeller was only tested with the pylon + fuselage configuration. The support pylon was fixed at the "nominal" pylon-rotor spacing, which resulted in a $7.0 \mathrm{~cm}(2.8 \mathrm{in}$. axial spacing between the pylon trailing edge and the forward propeller pitch change axis. The radial distance between the inner flow surface (rotor hub) and the simulated fuselage was $23.2 \mathrm{~cm}(9.1 \mathrm{in.})$ at the forward rotor plane, and $28.9 \mathrm{~cm}(11.4 \mathrm{in.})$ at the aft rotor plane. This resulted in a radial blade-tip-to-fuselage separations of $5.1 \mathrm{~cm}(2.0)$ in. for the forward rotor (F7) for both propellers, $11.3 \mathrm{~cm}(4.5 \mathrm{in.)}$ for the aft A7 rotor, and $15.4 \mathrm{~cm}$ (6.1 in.) for the aft $A 3$ rotor.

The simulated fuselage had a total length of $224 \mathrm{~cm}(88.2 \mathrm{in.})$. The maximum diameter of $63.5 \mathrm{~cm}(25.0 \mathrm{in.})$ occurred $47.2 \mathrm{~cm}(18.6 \mathrm{in}$.$) downstream of$ the highlight. The fuselage had a constant $9.24^{\circ}$ taper downstream of this maximum diameter. The fuselage was mounted with the propeller in such a way that its axis of rotation was tilted downward $3.5^{\circ}$ in the upstream direction. This resulted in the fuselage surface nearest to the propeller having an effective $5.75^{\circ}$ taper relative to the free-stream tunnel flow (and propeller axis of rotation). Table I presents additional dimensions for the simulated pylon and fuselage.

Figure 3 is a sketch of the installed propeller in the anechoic wind tunnel. The forward rotors of both propellers rotated in a clockwise direction viewing downstream; the aft rotors rotated in a counterclockwise direction. The circumferential locations of the sideline directivities are referenced in figure 3 as $\phi=0,90$, and $180^{\circ}$. The track probe was fixed at the $180^{\circ}$ circumferential location. The installed propeller was intended to simulate an aircraft pusher configuration. Such an aircraft would have symmetrical engine installations on either side of the fuselage using the same basic propeller. These two engines would have different directions of rotation relative to the airplane fuselage. That is, while the forward rotor of the "engine" sketched in figure 3 might rotate "inboard up," the forward rotor of the engine mounted on the opposite side of the fuselage would then rotate "inboard down." A similar relationship would exist for the aft rotors of the two engines. Thus, sideline data for the first installed engine at sideline data for the first installed engine at $\phi=0^{\circ}$ would correspond to installed data for the second engine at $\phi=180^{\circ}$.

Table II presents selected design parameters for the F7/A7 and F7/A3 propellers. As previously mentioned, the $A 3$ rotor had a reduced diameter which was intended to minimize its interaction with the forward, F7, rotor's tip vortex, and hence, result in lower interaction tone levels. The two propellers were designed for similar aerodynamic performance. Figure 4 shows photographs 
of the two propellers. The A3 rotor had a larger chord to compensate for the reduced diameter; however, its leading edge to pitch change axis was similar to that of the $A 7$ rotor to maintain nearly the same rotor-rotor aerodynamic spacing (affected by blade setting angle) for the same axial rotor-rotor spacing for the two propellers. Both propellers were tested at the "maximum" axia) rotor-rotor spacing of $14.99 \mathrm{~cm}(5.90 \mathrm{in.})$. The $A 3$ rotor was tested at a higher blade setting angle $\left(46.4^{\circ}\right)$ compared to that of the A7 rotor $\left(39.4^{\circ}\right.$ ) to achieve the same thrust. Reference 2 also showed that the rotor-alone tone level for the $A 3$ rotor was typically $7 \mathrm{~dB}$ lower than that for the $A 7$ rotor even though they were both at the same aerodynamic operating points. This tone level difference was attributed to the lower rotational tip speed of the A3 propeller - a consequence of its smaller diameter at the same rotational speed.

The installed configuration introduces a number of possible noise generation mechanisms. As shown in the cross-section sketch of figure 5 , the upstream pylon wake could easily interact with the propellers to generate pylon-rotor interaction tones at nBPF $f$ and $m B P F_{a}$, where $n$ and $m$ are integers. The simulated fuselage was much too short to generate boundary layer thicknesses comparable to those of an actual fuselage. However, the presence of this simulation could still introduce some boundary layer interaction with the propeller blades, and there could be other flow fields associated with this "fuselage" as we11. Reference 2 showed that there was an interaction tone reduction associated with the reduced diameter of the $A 3$ rotor. It is possible that acoustic benefits of reducing the aft rotor diameter could extend to the present study in that the $A 3$ rotor tip is further removed from the fuselage-induced flow disturbances as well as the $F 7$ rotor tip vortex.

\section{RESULTS AND DISCUSSION}

All tests were performed at 0.20 tunnel Mach number. Limited aerodynamic results are presented to establish the propeller operating conditions. Acoustic results are presented as sideline directivities for the track and polar probes. Results are presented for both probes at $\phi=180^{\circ}$, with additional results for the polar probe at $\phi=0$ and $90^{\circ}$. Test results in this paper are for $0^{\circ}$ propeller axis angle of attack.

\section{Aerodynamic Performance}

Figure 6 is a propeller operating map of the total power density based on the forward rotor annulus), PQAT, as a function of the forward rotor advance ratio, Jf. PQAT is defined as:

$\frac{\text { total power }}{(p)(\text { rev/sec })^{3}\left(D^{3}\right) \text { (annulus area) }}$

where $\rho$ is the local air density, and $D$ is the forward propeller diameter. The results are shown in figure 6 for both the baseline and the pylon + fuselage configurations for each propeller. The addition of the simulated pylon + fuselage causes essentially no change in the operating line for each propeller - 
especially at the higher rotational speeds (lower $\mathrm{J}$ ). The difference in the PQAT values for the two propellers at a particular $J$ value is on the order of 0.15 , and is considered insignificant with respect to acoustic performance.

\section{Acoustic Performance}

Sound pressure level spectra. - The acoustic spectra for counterrotation propellers may be quite complex, consisting of both steady loading and thickness rotor-alone tone harmonics for each rotor, and an array of interaction tones. Figure 7 presents typical spectra for the F7/A7 propeller in the baseline and pylon + fuselage configurations at the $\phi=180^{\circ}$ circumferential location. These results are from the polar microphone probe at a $61 \mathrm{~cm}$ (24 in.) sideline approximately $65^{\circ}$ from the upstream propeller axis $\left(\theta=65^{\circ}\right)$ relative to the aft rotor plane. Rotor-alone tones tend to show a sideline maximum level near the rotor plane $\left(\theta=90^{\circ}\right.$, while interaction tones of ten show highest levels away from this location. The various tone orders are denoted in figure $7(a)$ for the rotor-alone configuration. The first order rotor-alone tones for the forward and aft rotor $\left(B_{f}\right.$ and $B_{a}$ ) are clearly evident. These tones typically show higher levels near the rotor plane. Higher order rotoralone tones are not evident in this spectra since they are buried in the broadband. The first interaction tone $\left(B_{f}+B_{a}\right)$ is quite evident, as are the higher-order interaction tones. The corresponding results for the pylon + fuselage configuration ( $f i g .7(b)$ ) taken at the same sideline location and propeller operating condition) show that the first order rotor-alone tone levels are increased by the presence of the simulated installation. However, the interaction tone levels are essentially unaffected by this installation. In this installation interaction tones are of two types: pylon-rotor interactions at $n B P_{f}$ and $m B P F_{a}$, and rotor-rotor interactions at $n B P_{f}+m B P F_{a}$, where $n$ and $m$ take on all possible combinations of integer values.

Sideline directivities at $\phi=180^{\circ}$ circumferential position. - Sideline directivities are presented at this location for both the polar probe (at $61 \mathrm{~cm}$ (24 in.)) sideline and the track probe (at $137 \mathrm{~cm}$ (54 in.)) sideline. Similar data are presented for both sidelines to show how the acoustic field varies with distance from the propeller. Earlier tests in the 9-by 15-Foot Anechoic Wind Tunnel have indicated that both probes were measuring the far field for the propeller baseline configuration. However, acoustic reflections from the simulated installation could easily affect this comparison. Data are presented for the first and second order rotor-alone tones and for the first two interaction tones.

Figures 8 and 9 show the effect of the installation on the F7/A7 propeller rotor-alone tones at 90 percent design rotational speed. Figure 8 presents results for the $61 \mathrm{~cm}$ sideline, while figure 9 presents corresponding results for the $137 \mathrm{~cm}$ sideline. The two rotors would be expected to experience inflow disturbances in presence of the pylon + fuselage (figs. 3 and 5). Both figures show the aft rotor-alone tone increasing at $\phi=180^{\circ}$ while the front rotor-alone tone decreases. Rotor-alone steady and unsteady loading noise is generated normal to the advancing propeller blade, and one would expect to observe noise increases at the $180^{\circ}$ position for the aft rotor. This tone increase is indeed present for the aft rotor in figures 8 and 9. The forward rotor shows a comparable tone level decrease at this circumferential location $\left(\phi=180^{\circ}\right)$. The reason for this tone decrease is not known. Although trends are consistent, the near and farfield levels are different. 
In particular, the tone level change for the closer polar probe is on the order of $10 \mathrm{~dB}$, while that for the track probe is a more modest $4 \mathrm{~dB}$. A comparison of directivity shapes can be somewhat misleading in that the track probe covered a larger angular distance than did the polar probe, hence the two directivities are on different angular scales. Also, spherical spreading considerations would predict a $7 \mathrm{~dB}$ difference in the sound pressure levels measured at the two sideline distances.

Figures 10 and 11 show the effect of the installation on the F7/A7 propeller rotor-alone tones at 80 percent design speed. The same trends are generally evident, with the aft rotor showing a tone level increase of about $10 \mathrm{~dB}$ at both sideline distances. The installation acoustic effect on the forward rotor is much less at this rotational speed, with the polar probe directivity even showing a small tone level increase with the installation at the aft sideline angles.

Figures 12 to 15 show the effect of the installation on the first two interaction tones at 80 and 90 percent design propeller speed. Results are shown for the $61 \mathrm{~cm}$ sideline polar probe and for the $137 \mathrm{~cm}$ sideline track probe. There is a small level increase at both sideline distances for the first interaction tone $\left(B P F_{f}+B P F_{a}\right)$ at 90 percent speed near the $50^{\circ}$ sideline angle (figs. 12 and 13, part (a)). The maximum sideline level for the second interaction tone $\left(2 B P F_{f}+B P F_{a}\right)$ showed essentially no change with the installation in place. However, the angular structure of the lobular pattern shifted somewhat with the simulation in place at the closer sideline (fig. $12(\mathrm{~b})$ ).

Figures 14 and 15 present the sideline directivities for the first two interaction tones at 80 percent design propeller speed. The second interaction tone shows a small increase with the installation in place at both sideline distances ( $f i g s .14$ and 15, part (b)), while the first interaction tone showed a small increase only at the further $(137 \mathrm{~cm})$ sideline.

Figure 16 shows the maximum noise level that was measured along the $137 \mathrm{~cm}$ sideline (track probe) as a function of percent of design propeller speed. Figure 16(a) shows that the trend for the forward rotor to show a level decrease and the aft rotor to show a level increase with the installation in place is typical of all test speeds. However, the decrease for the forward rotor only becomes significant at 80 percent speed and above, while the tone increase for the aft rotor shows a maximum value at the lower propeller speeds. Results for the first two interaction tones are shown in figure $16(b)$. The first interaction tone, $B P F f+B P F_{a}$ shows a small level increase with the installation in place throughout the propeller speed range; while the second tone, $2 \mathrm{BPF}_{\mathrm{f}}+\mathrm{BPF}_{\mathrm{a}}$ shows a corresponding decrease in level.

Figures 17 to 20 show the effect of the installation on the rotor-alone tones of the F7/A3 propeller. Again, the A3 rotor featured a reduced diameter which should somewhat reduce that rotor's response to flow disturbances near the simulated fuselage. The F7/A3 propeller shows the same response as was seen for the F7/A7 propeller. That is, the aft rotor-alone tone shows an increase in the presence of the installation, while the forward rotor tone shows a decrease in level. The rotor-alone tones show level changes of about $8 \mathrm{~dB}$ at the closer sideline distance at 90 percent design speed ( $\mathrm{fig} .17$ ). The tone level decrease for the forward rotor is about the same as the increase for the aft rotor. There is a similar trend in the 90 percent 
speed results at the $137 \mathrm{~cm}$ sideline ( $f$ ig. 18), with the aft rotor again showing up to an $8 \mathrm{~dB}$ increase with the installation. The decrease for the forward rotor at the track sideline distance is only about $3 \mathrm{~dB}$.

The acoustic effect of the installation on the F7/A3 forward rotor-alone tone at 80 percent design speed is only about a $3 \mathrm{~dB}$ decrease at the closer sideline distance ( $f i g .19$ ), and essentially no effect at the $137 \mathrm{~cm}$ sideline (fig. 20). The aft rotor-alone tone shows about a $7 \mathrm{~dB}$ increase at both sideline distances with the simulated installation in place. Thus, the aft rotoralone tone is seen to show a substantial level increase, while the forward rotor-alone tone shows a similar level decrease with the presence of the installation. There are some differences in corresponding directivities at the two sideline distances which may be due to acoustic reflections from the installation. The level decrease for the forward rotor-alone tone with the installation is less than the corresponding aft rotor-alone tone increase at 80 percent design speed, unlike the results for 90 percent speed where the forward rotor-alone tone level decrease is of a similar magnitude to the aft rotor-alone tone increase.

Effect of pylon-alone on installed noise. - The pylon-alone configuration was only tested with the F7/A3 propeller. Acoustic interaction of the pylon wake with the propeller was expected to be a major contributor to the installed propeller noise. References 5 to 7 present results for other model counterrotation propellers which were tested with upstream simulated support pylons. A relatively lowly-loaded model propeller was tested with a simulated upstream pylon (refs. 5 and 6) which showed tone increases up to $7 \mathrm{~dB}$ with the pylon in place. However, another more highly-loaded advanced propeller showed only an average of 1 EPNdB (within data scatter) increase with an upstream pylon in place (ref. 7), suggesting that the acoustic effect of the upstream pylon may decrease with increased propeller loading. The propellers in the present study are more typical of that of reference 7 . That is, the more highly-loaded propeller experiences a smaller percent change in loading due to similar inflow disturbances.

Figures 21 and 22 show the effect of the pylon on the $F 7 / A 3$ propeller sideline directivities. Results for the polar microphone at the closer, $61 \mathrm{~cm}$ sideline distance ( $f i g .21$ ) show that there is no significant pylon-induced noise for either rotor at 80 and 90 percent design speed. However, there is an indication of pylon-induced rotor-alone noise for the directivities measured at the $137 \mathrm{~cm}$ track probe sideline ( $\mathrm{fig} .22$ ). At 90 percent speed the presence of the pylon increased the aft rotor-alone tone level as much as $5 \mathrm{~dB}$, although there was no corresponding decrease in the forward rotor-alone tone level, as was typical for the complete pylon + fuselage installation. The 80 percent design speed results in figure 22 show that the presence of the pylon causes a small decrease in the forward rotor-alone tone level, and small increases in the aft rotor-alone tone. These data again show that there is a difference in the installed propeller rotor-alone tone directivities at the two sideline distances.

It is possible that the higher-order rotor-alone tones could be more sensitive to the upstream pylon disturbance. Figure 23 shows the $2 B P F_{f}$ sideline directivities at the closer, $61 \mathrm{~cm}$ distance. There is little indication of pylon-induced noise for this tone at either 80 or 90 percent design speed. However, the tone levels were frequently merged into the broadband levels especially at 80 percent design speed. It was impossible to identify the 
$2 \mathrm{BPF}_{\mathrm{a}}$ tones at the $61 \mathrm{~cm}$ sideline, as was the case for both $2 \mathrm{BPF}$ tones at the $137 \mathrm{~cm}$ sideline. Thus, it is possible that signal enhancement might be used to show a pylon effect for this tone order.

Figures 24 to 27 show the sideline directivities for the first two F7/A3 interaction tones at 80 and 90 percent design speed. Results are shown for both sideline distances. Again, the presence of the installation had little effect on the interaction tone levels. It is interesting to note that the sideline interaction tone directivities for the F7/A3 propeller have a significantly different structure than do the corresponding sideline interaction tone directivities for the $F 7 / A 7$ propeller (figs. 12 to 15), indicating that interaction tone generation mechanisms (modes) for the reduced-diameter A3 rotor are different than those for the $A 7$ rotor.

Figure 28 summarizes the maximum tone levels along the $137 \mathrm{~cm}$ sideline for the F7/A3 propeller as a function of propeller speed. The forward rotor-alone tone ( $f i g .28(a)$ ) again shows a small level decrease with the installation in place for all propeller speeds except 75 percent speed. The aft rotor-alone tone ( $f$ ig. $28(\mathrm{~b})$ ) shows the expected increase in tone level throughout the speed range. The first two interaction tones ( $f i g .28(c)$ and (d)) show little sensitivity to the presence of the simulated installation.

Figure 29 summarizes the relative installation effects (pylon + fuselage) for the two test propellers, showing the maximum tone level as a function of percent design propeller speed along the $137 \mathrm{~cm}$ sideline at the $180^{\circ}$ position. The forward rotor-alone tone ( $f i g .29(a)$ ) is for the $F 7$ rotor in both propellers at a setting angle of $41.1^{\circ}$. As should be expected, the acoustic performance is generally similar for both propellers, showing a small tone reduction at the $180^{\circ}$ position with the installation in place.

The rotor-alone tone for the aft rotor shows a significant increase at the $180^{\circ}$ position with the installation in place. As shown in figure 29(b), there is up to an $8 \mathrm{~dB}$ peak tone level increase associated with the presence of the installation. The tone level for the $A 3$ rotor (baseline and installed) are typically $7 \mathrm{~dB}$ lower than those for the $A 7$ rotor, and this difference relates to the lower tip speed of the $A 3$ rotor.

The first interaction tone $\left(B P F_{f}+B P F_{a}\right.$ ) shows a small increase for both propellers with the installation in place ( $f$ ig. $29(\mathrm{c})$ ). However, this tone level for the F7/A7 propeller is significantly higher than that for the $F 7 / A 3$ propeller - especially at the lower speeds. The A3 rotor was designed with a reduced diameter to significantly reduce the rotor's interaction with the upstream rotor's tip vortex. The first interaction tone results of figure $29(\mathrm{c})$ illustrate the general tone reduction from reduced aft rotor diameter. Also, the tone level increase with the installation in place is slightly higher for the F7/A7 propeller. Similar results are shown for the second interaction tone $\left(2 B P F_{f}+B P F_{a}\right)$ in figure $29(d)$.

Interaction tones for a counterrotation propeller can result from the aft rotor interacting with the upstream rotor viscous wake and tip vortex; or possibly from the forward rotor interacting with the downstream rotor potential field. As was previously mentioned, the $A 3$ rotor had a reduced diameter which was shown (ref. 2) to reduce the interaction tone levels by avoiding interaction with the upstream rotor tip vortex. It is possible that the upstream vortex of the $F 7$ rotor is further disturbed by the presence of the simulated 
installation (fig. 5). This disturbed vortex would then interact with the downstream A7 rotor, but possibly not with the downstream A3 rotor. This concept may explain why the interaction tones for the F7/A7 propeller were influenced by the presence of the installation while the those for the F7/A3 propeller showed no change.

Sideline directivities at $\phi=0^{\circ}$ circumferential position. - The previous discussion showed that the aft propeller rotor-alone tone showed a significant level increase at the $180^{\circ}$ circumferential position. This is consistent with the idea that tone noise is radiated normal to the advancing propeller blade and that a noise increase might be expected when the blade encounters a flow disturbance, such as that caused by the simulated installation (fig. 3 ). By this same argument, the forward rotor would be expected to show a similar rotor-alone tone increase at the opposite side of the model propeller. The following sideline directivity results are for the polar probe $(61 \mathrm{~cm}$ sideline) at the $0^{\circ}$ circumferential location. (The $137 \mathrm{~cm}$ sideline track microphone probe, being fixed to the tunnel floor, could only survey the $\phi=180^{\circ}$ position).

Figures 30 and 31 show the sideline rotor-alone tone directivities for the F7/A7 propeller at 80 and 90 percent design speed. These results do show that the forward rotor tone level increases with the presence of the installation. Likewise, there is a corresponding decrease in the tone level for the aft rotor. It is interesting to note that the tone level increase for the forward propeller occurs forward of the propeller plane at 90 percent speed ( $f i g .30$ ), and aft of that location at the lower speed (fig. 31). The reason for this change in directivity with propeller speed is unknown.

The rotor-alone tone directivities for the F7/A3 propeller are shown in figures 32 and 33 . There are small increases in the forward rotor-alone tone levels at 90 percent speed ( $f i g .32$ ) and at 80 percent speed (fig. 33). The aft tone also shows an unexpected small increase at 90 percent speed, but not at the lower speed. In general, the changes in the rotor-alone tone level for both propellers is smaller at this circumferential location than was observed at the $180^{\circ}$ location.

Figure 34 shows the effect of the pylon-alone configuration on the F7/A3 propeller rotor-alone tones at the $0^{\circ}$ circumferential location. Again, these results show that the pylon, by itself, has relatively little effect on the rotor-alone tone levels.

Figure 35 shows forward 2BPF rotor-alone tone sideline directivities at 80 and 90 percent speed. These results clearly show that the presence of the pylon alone (and the complete installation) significantly increases this tone level at the $0^{\circ}$ position. At 80 percent design speed (fig. 35(a)), there is up to a $9 \mathrm{~dB}$ tone level increase with the pylon in place, with the presence of the complete installation causing additional noise at the aft angles. A similar effect is seen at 90 percent design speed ( $\mathrm{fig} .35(\mathrm{~b})$ ) although the tone level increase is not quite as great. These results show that the second order rotor-alone tone is much more sensitive to the presence of the pylon than was the first order tone at this $0^{\circ}$ circumferential position.

Sideline directivities at $\phi=90^{\circ}$ circumferential location. - Figures 36 and 37 show the $61 \mathrm{~cm}$ sideline directivities at the $90^{\circ}$ circumferential location, which was diametrically opposite from the location of the simulated 
fuselage (fig. 3). Results are shown for the F7/A7 propeller (fig. 36) and the F7/A3 propeller ( $f i g .37$ ) operating at 90 percent design speed. Both the forward and aft rotor-alone tones show a significant increase with the simulated installation in place. Similar results were also observed in the 80 percent speed data.

It is possible that there is a delay in the blades acoustic response to the disturbance gust. If this delay were on the order of $45^{\circ}$ of rotation, then the region of maximum rotor-alone noise would occur at $45^{\circ}$ on either side of the $90^{\circ}$ location. This response delay would tend to explain the high tone levels observed at $90^{\circ}$ with the installation in place.

\section{SUMMARY OF RESULTS}

Two advanced counterrotation propellers were acoustically tested in the NASA 9- by 15- Foot Anechoic Wind Tunnel at a simulated takeoff/landing speed of $0.20 \mathrm{Mach}$. The propellers were tested in the baseline configurations and with a simulated pusher support pylon + fuselage in place to investigate installed noise effects. The propellers were tested over a range of rotational speeds at $0^{\circ}$ propeller axis angle of attack. Acoustic data were taken with a translating sideline microphone which was mounted on the tunnel floor and with a polar microphone which was attached to the downstream propeller housing and could survey both sideline and circumferential noise directivities. The following significant results were observed in this study:

1. Fundamental installation-rotor interaction tones increased by as much as $10 \mathrm{~dB}$ at a circumferential sideline location normal to the advancing propeller blade as it passed the simulated fuselage.

2. A corresponding tone decrease of similar magnitude was often observed for the same rotor-alone tone at a circumferential location diametrically opposite of the maximum noise location, indicating that the noise of an installed propeller may be lower at some circumferential locations.

3. Pylon - fuselage rotor-alone tones for both propellers always showed a region of increased tone level which was located circumferentially outboard of the fuselage.

4. The second-order forward rotor-alone tone showed a significant level increase with the pylon-only installed at a circumferential sideline location normal to the advancing propeller as it passed the pylon. The pylon-only configuration had essentially no effect on the first order rotor-alone tone levels at the closer $(61 \mathrm{~cm})$ sideline. However, the pylon-only installation was shown to cause a modest increase in the aft rotor-alone tone level at the further $(137 \mathrm{~cm})$ sideline.

5. Interaction tones for the F7/A7 propeller, were also affected by the presence of the simulated installation, showing small changes (increases and decreases) at the $137 \mathrm{~cm}$ (54 in.) sideline location.

6. Interaction tones for the F7/A3 propeller were essentially unaffected by the presence of the simulated installation, indicating that the reduced diameter of the $A 3$ rotor may contribute to this insensitivity. 


\section{REFERENCES}

1. Mikkelson, D.C., Mitchell, G.A. and Bober, L.J., "Summary of Recent NASA Propeller Research," Aerodynamics and Acoustics of Propellers, AGARD CP-366, AGARD, Neuilly-Sur-Seine, France, 1985, pp. 12-1 to 12-24. (NASA TM-83733).

2. Woodward, R.P., and Gordon, El iott B., "Noise of a Model Counterrotation Propeller with Reduced Aft Rotor Diameter at Simulated Takeoff/Approach Conditions," AIAA Paper 88-0263, NASA TM-100254, 1988.

3. Dittmar, J.H., "Some Design Philosophy for Reducing the Community Noise of Advanced Counter-Rotation Propellers," NASA TM-87099, 1985.

4. Dittmar, J.H., and Stang, D.B., "Noise Reduction for Model Counterrotation Propeller at Cruise by Reducing the Aft-Propeller Diameter," NASA TM-88936.

5. Block, P.J.W., Klatte, R.M., and Druez, P.M., "Counter-Rotating Propeller Noise Directivity and Trends," AIAA-86-1927, 1986.

6. Block, P.J.W., "Pusher Propeller Noise Directivity and Trends," AIAA-86, $1929,1986$.

7. Magliozzi, B., "Noise Characteristics of a Model Counterrotating Prop-Fan," AIAA-87-2656, 1987. 
TABLE I. - SIMULATED INSTALLATION DIMENSIONS

[Dimensions in $\mathrm{cm}$ (in.).]

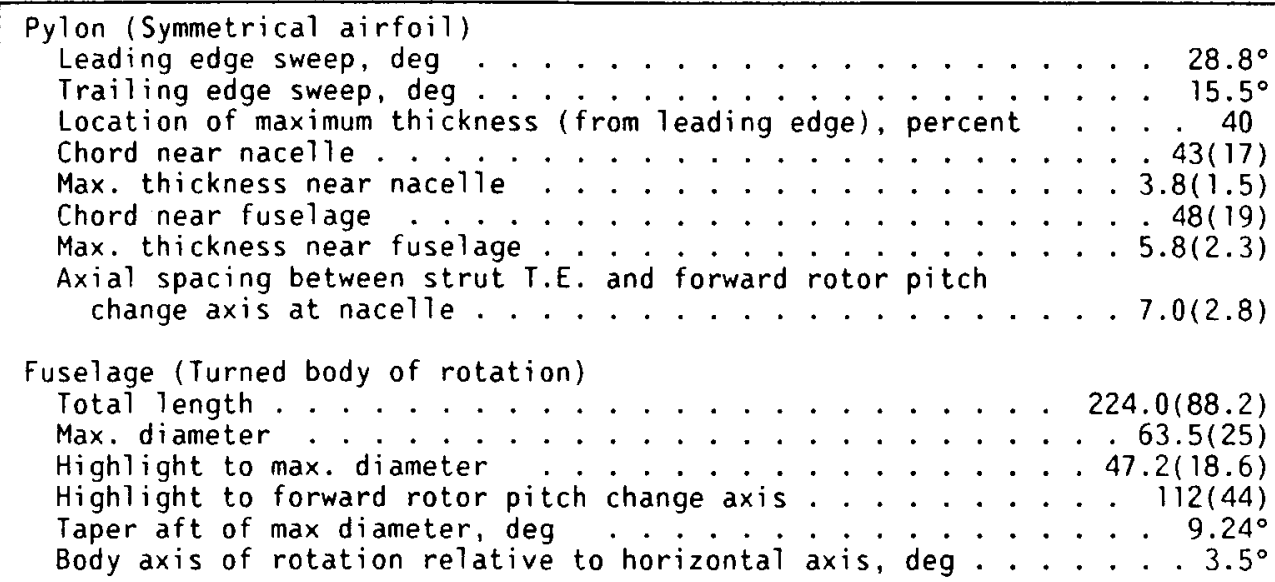

TABLE II. - PROPELLER DESIGN CHARACTERITISTICS [Cruise conditions.]

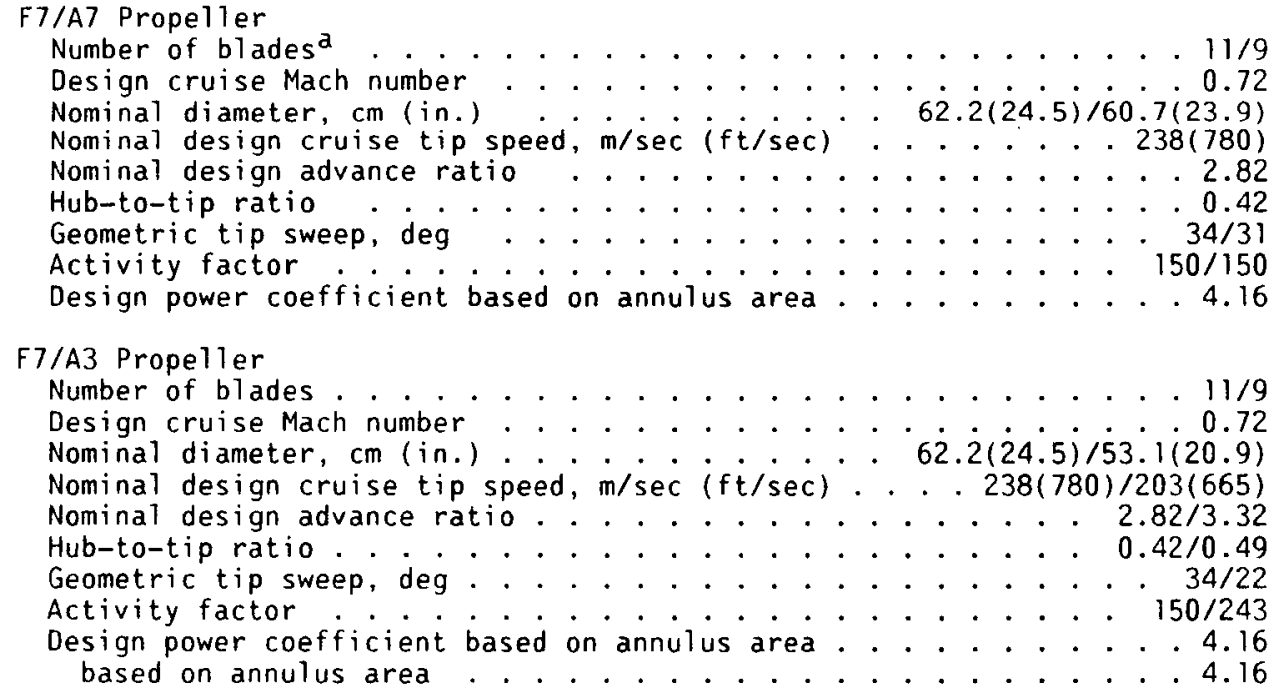

a forward propeller/aft propeller 


\section{ORIGINAL PAGE \\ BLACK AND WHITE PHOTOGRAPH}

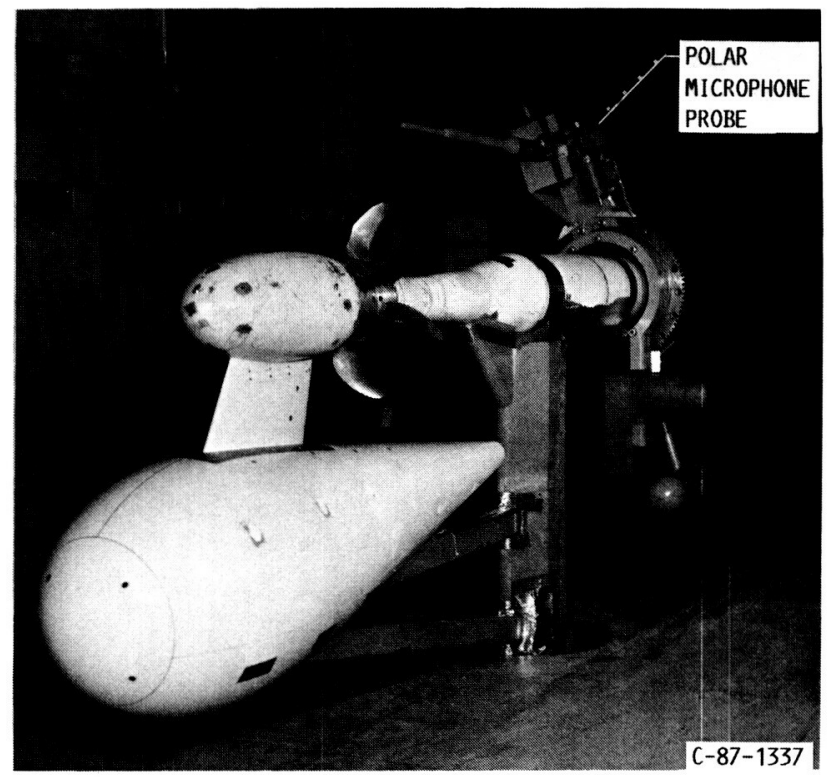

FIGURE 1. - COUNTERROTATION TURBOPROP MODEL IN $9 \times 15$ ANECHOIC WIND TUNNEL - SHOWN WITH SIMULATED SUPPORT PYLON + FUSELAGE CONFIGURATION.

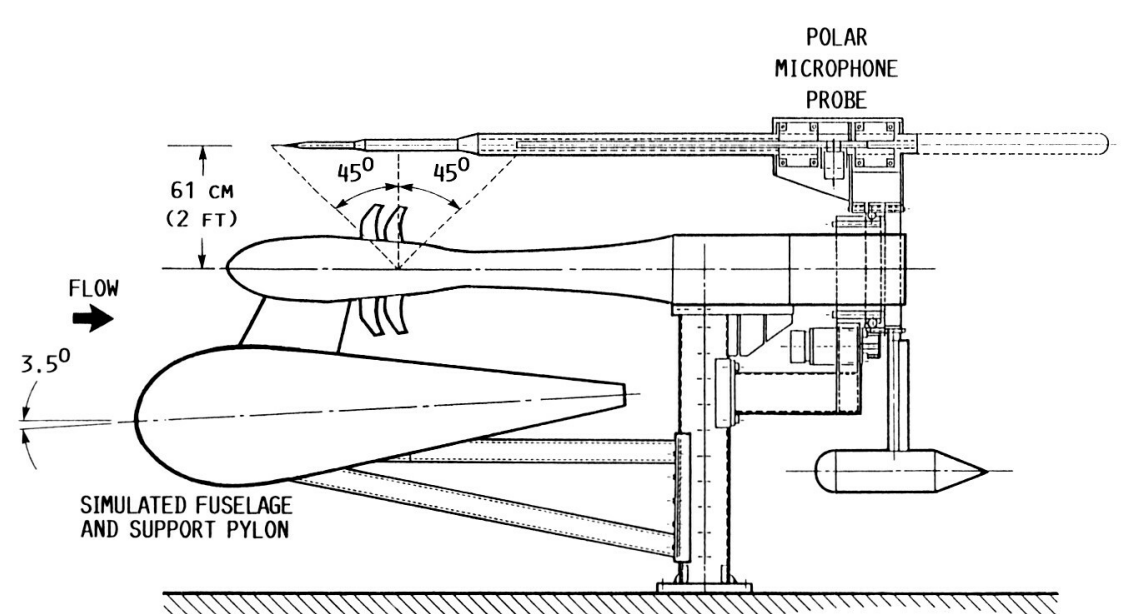

FIGURE 2. - SKETCH OF THE TURBOPROP MODEL AND POLAR MICROPHONE PROBE.

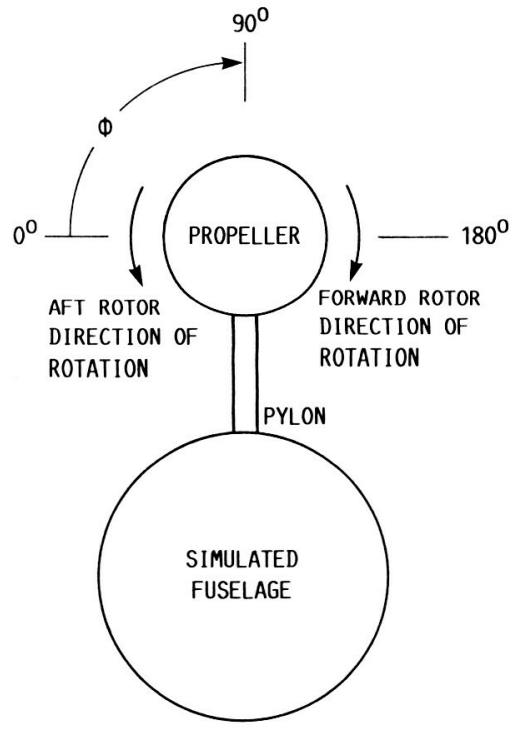

FIGURE 3. - SKETCH OF INSTALLED PROPELLER VIEWING DOWNSTREAM SHOWING DIRECTIONS OF ROTATION AND CIRCUMFERENTIAL ANGLE CONVENTION FOR NOISE MEASUREMENTS. 
ORIGINAL PAGE

BLACK AND WHTTE PHOTOGRAPH

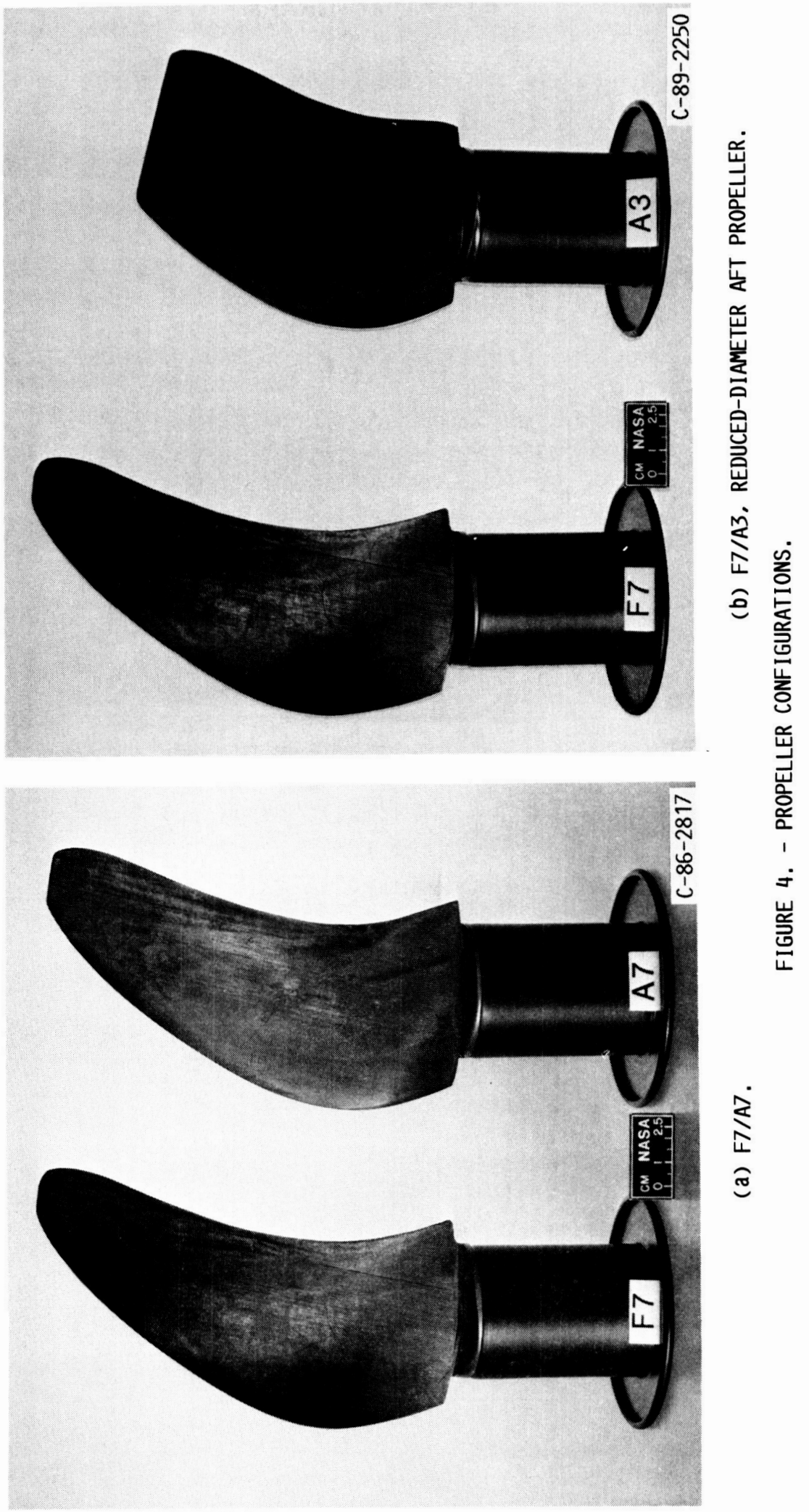




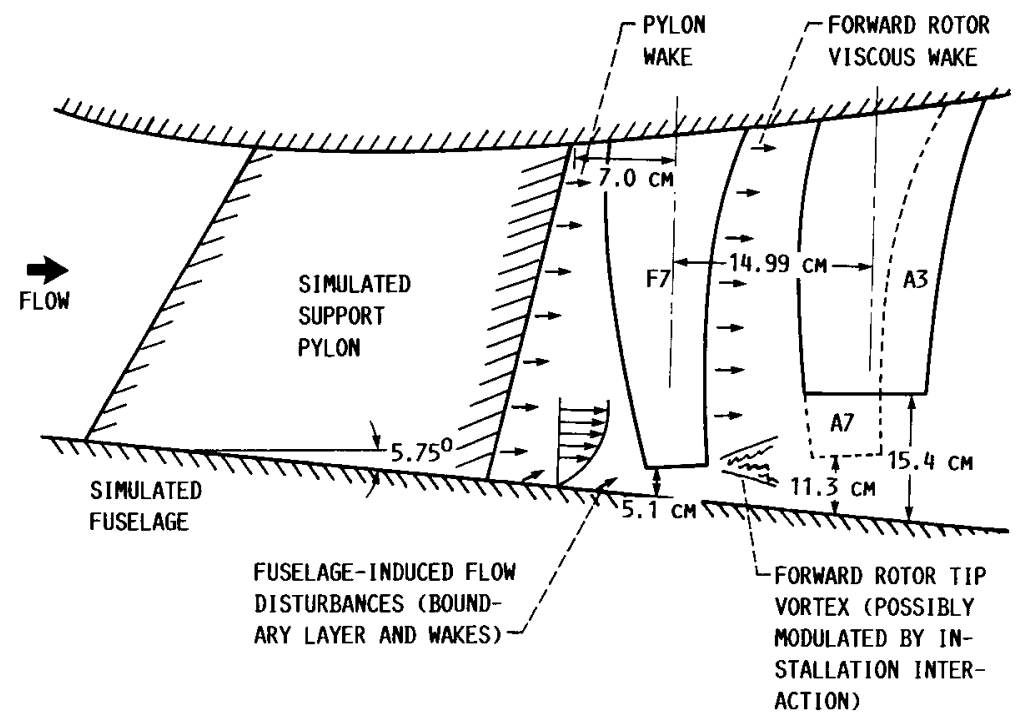

FIGURE 5. - POSSIBLE NOISE SOURCES FOR INSTALLED PROPELLER.
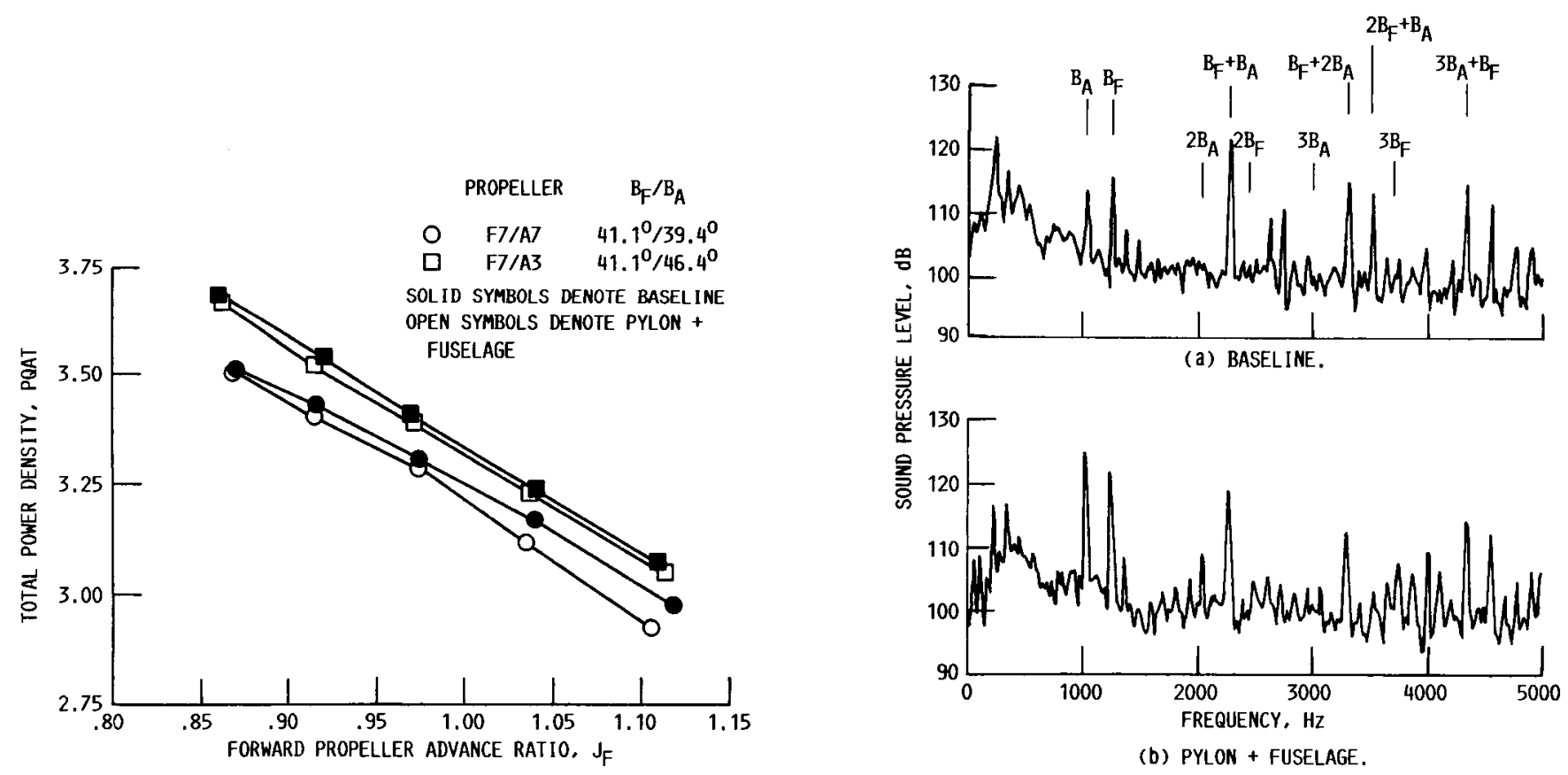

FIGURE 6. - PROPELLER OPERATING MAP FOR F7/A7 AND FT/A3 PROPELLERS ( $11 / 9$ BLADES, MAXIMUM ROTOR-ROTOR SPACING, $\alpha=0^{0} \cdot M_{\infty}=0.2$.

(b) PYLON + FUSELAGE.

FIGURE 7. - TYPICAL SIDELINE SOUND PRESSURE LEVEL SPECTRA FOR THE F7/A7 MODEL TURBOPROP (11/9 BLADES, 80\% SPEED, $\mathrm{B}_{\mathrm{F}} / \mathrm{B}_{\mathrm{A}}=41.1^{\circ} / 39.4^{\circ}, 61 \mathrm{cM}$ (24 IN.) SIDELINE. $\theta=65^{\circ}, \Phi=180^{\circ}, M_{\infty}=0.2$ ). 


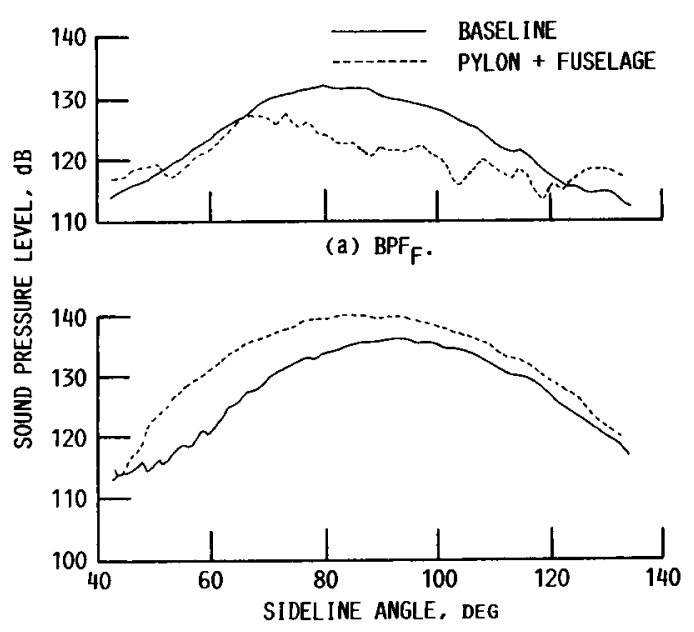

(b) $\mathrm{BPF}_{\mathrm{A}}$.

FIGURE 8. - EFFECT OF PYLON + FUSELAGE ON F7/A7 ROTOR-ALONE TONE SIDELINE DIRECTIVITY, $\Phi=180^{\circ}$, 90\% DESIGN SPEED (61 CM (24 IN.) SIDELINE. $\left.\alpha=0^{0}, M_{\infty}=0.2\right)$.

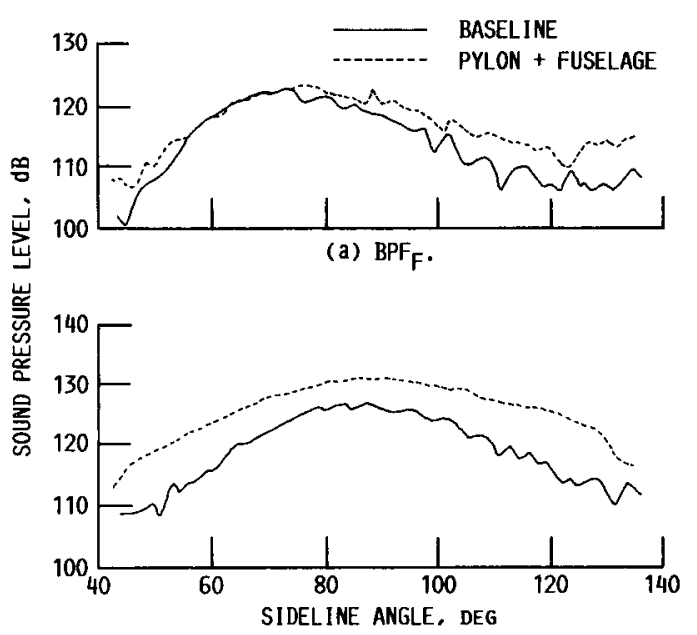

(b) $\mathrm{BPF}_{\mathrm{A}}$.

FIGURE 10. - EFFECT OF PYLON + FUSELAGE ON F7/A7 ROTOR-ALONE TONE SIDELINE DIRECTIVITY, $\Phi=180^{\circ}$. 80\% DESIGN SPEED (61 cM (24 IN.) SIDELINE. $a=0^{0}, M_{\infty}=0.2$ ).

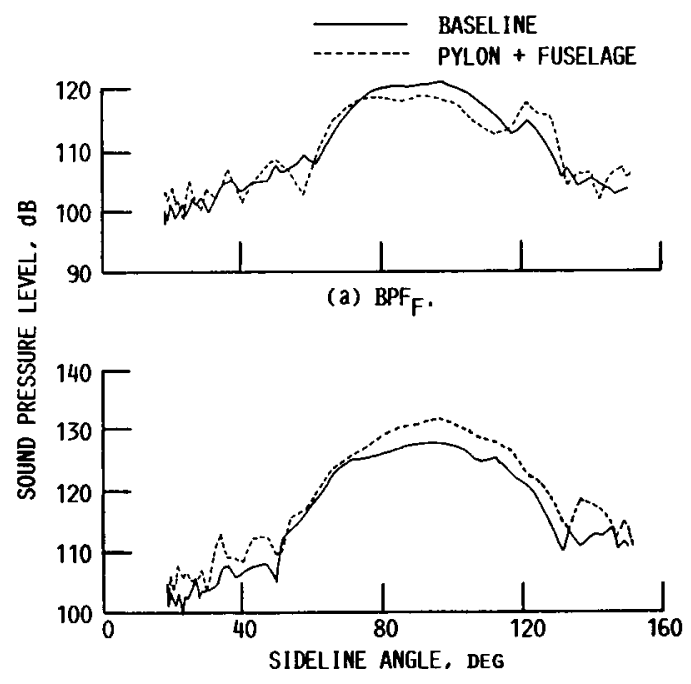

(b) $\mathrm{BPF}_{A}$.

FIGURE 9, - EFFECT OF PYLON + FUSELAGE ON F7/A7 ROTOR-ALONE TONE SIDELINE DIRECTIVITY, $\Phi=180^{\circ}$, 90\% DESIGN SPEED ( $137 \mathrm{~cm}$ (54 IN.) SIDELINE, $a=0^{0}, M_{\infty}=0.2$ ).

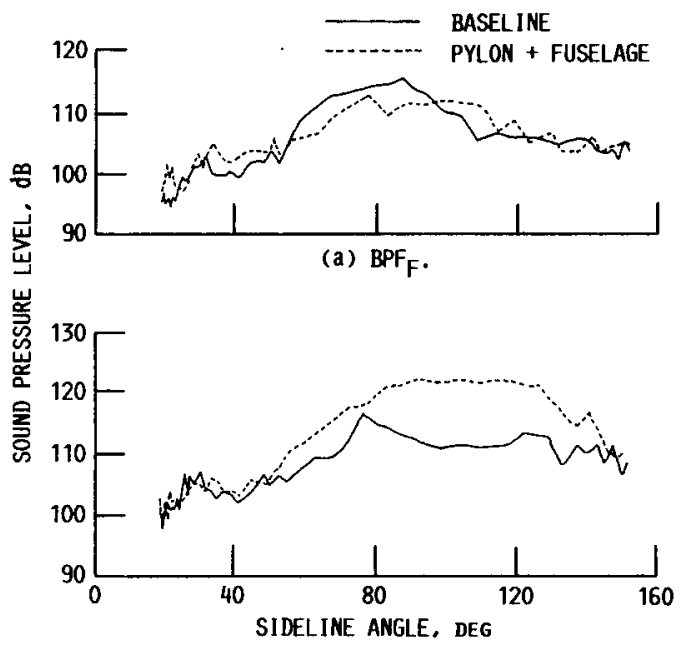

(b) $\mathrm{BPF}_{\mathrm{A}}$.

FIGURE 11. - EFFECT OF PYLON + FUSELAGE ON F7/A7 ROTOR-ALONE TONE SIDELINE DIRECTIVITY, $\phi=180^{\circ}$, 80\% DESIGN SPEED (137 cM (54 IN.) SIDELINE. $a=0^{0}, M_{\infty}=0.2$ ) 


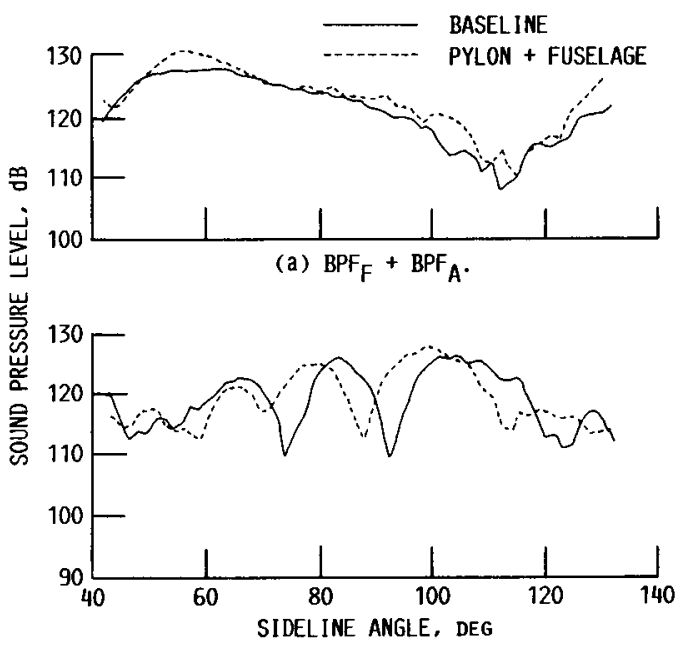

(b) $2 \mathrm{BPF}_{\mathrm{F}}+\mathrm{BPF}_{\mathrm{A}}$.

FIGURE 12. - EFFECT OF PYLON + FUSELAGE ON F7/A7 INTERACTION TONE SIDELINE DIRECIIVITY, $\Phi=180^{\circ}$, 90\% DESIGN SPEED (61 cM (24 IN.) SIDELINE, $a=0^{0}, M_{\infty}=0.2$ ).

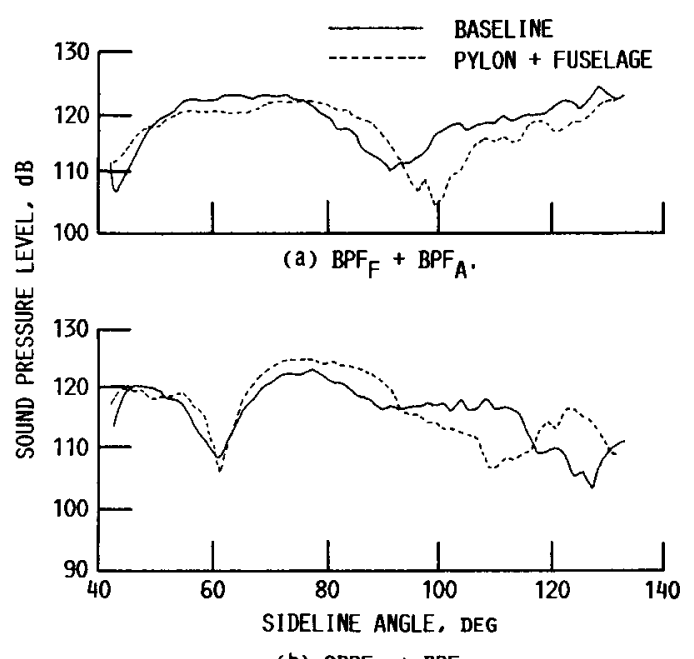

(b) $2 \mathrm{BPF}_{F}+\mathrm{BPF}_{\mathrm{A}}$.

FIGURE 14, - EFFECT OF PYLON + FUSELAGE ON F7/A7 INIERACTION TONE SIDELINE DIRECTIVITY, $\Phi=180^{\circ}$, 80\% DESIGN SPEED (61 cM (24 IN.) SIDELINE. $\left.\alpha=0^{0}, M_{\infty}=0.2\right)$.

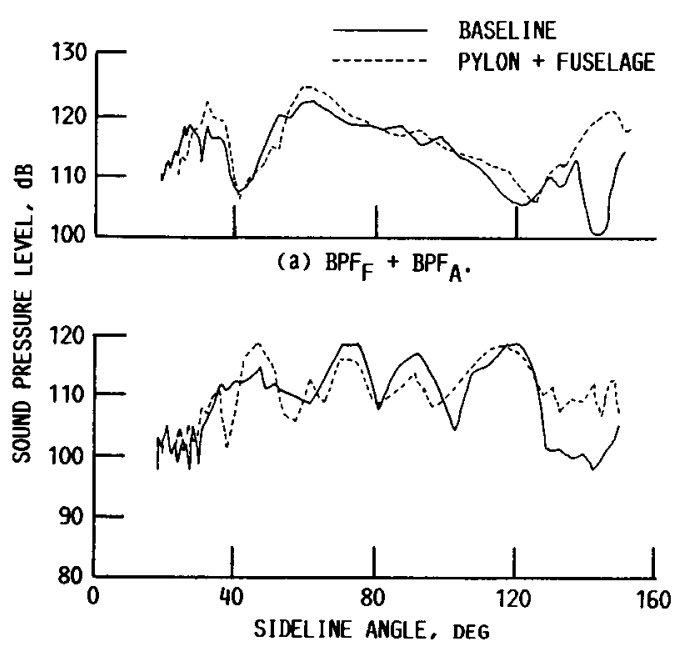

(b) $2 B P F_{F}+B P F_{A}$.

FIGURE 13. - EFFECT OF PYLON + FUSELAGE ON F7/A7 INTERACTION TONE SIDELINE DIRECTIVITY, $\Phi=180^{\circ}$. 90\% DESIGN SPEED (137 cM (54 IN.) SIDELINE, $\left.\alpha=0^{0}, M_{\infty}=0.2\right)$.

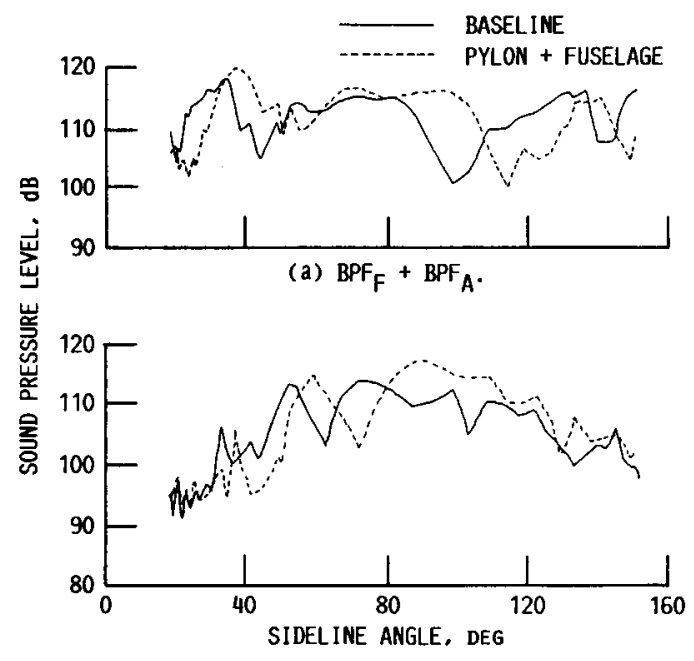

(b) $2 \mathrm{BPF}_{F}+\mathrm{BPF}_{\mathrm{A}}$.

FIGURE 15. - EFFECT OF PYLON + FUSELAGE ON F7/A7 INTERACTION TONE SIDELINE DIRECTIVITY, $\Phi=180^{\circ}$, 80X DESIGN SPEED (137 cM (24 IN.) SIDELINE. $\left.a=0^{0}, M_{\infty}=0.2\right)$. 


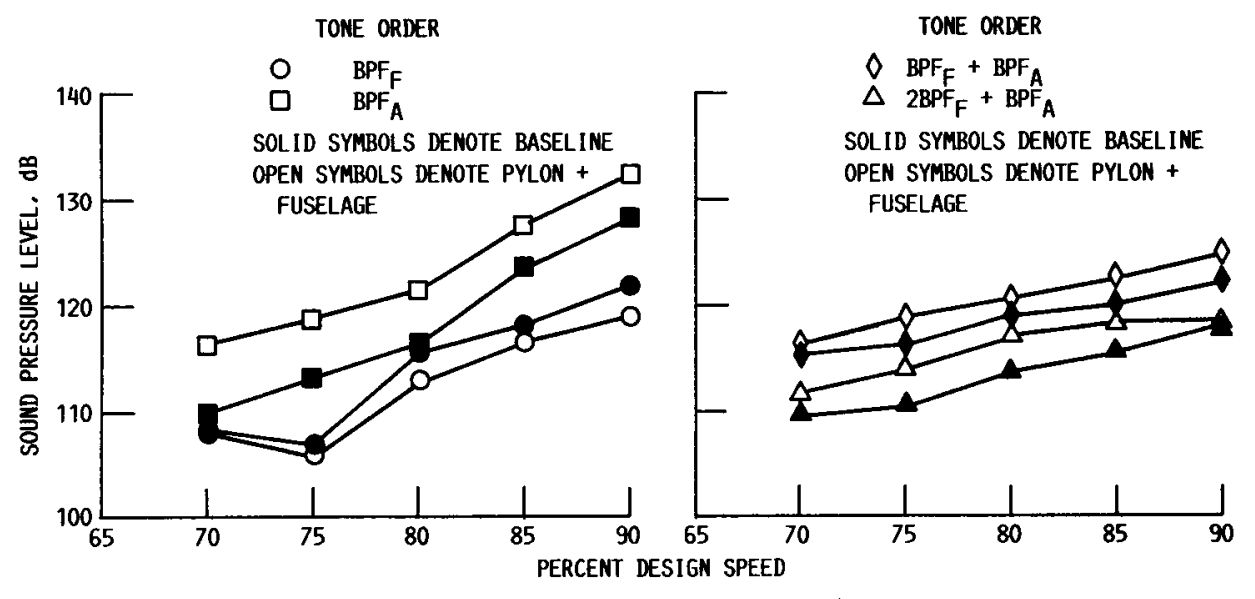

(a) ROTOR-ALONE TONES,

(b) INTERACTION TONES.

FIGURE 16. - EFFECT OF SIMULATED PYLON + FUSELAGE ON F7/A7 SIDELINE TONE LEVEL, $\Phi=180^{\circ}$

(137 CM (54 IN.) SIDELINE, $B_{F} / B_{A}=41.1^{0} / 39.4^{\circ}, \alpha=0^{\circ}, 11 / 9$ BLADES, $\left.M_{\infty}=0.2\right)$.

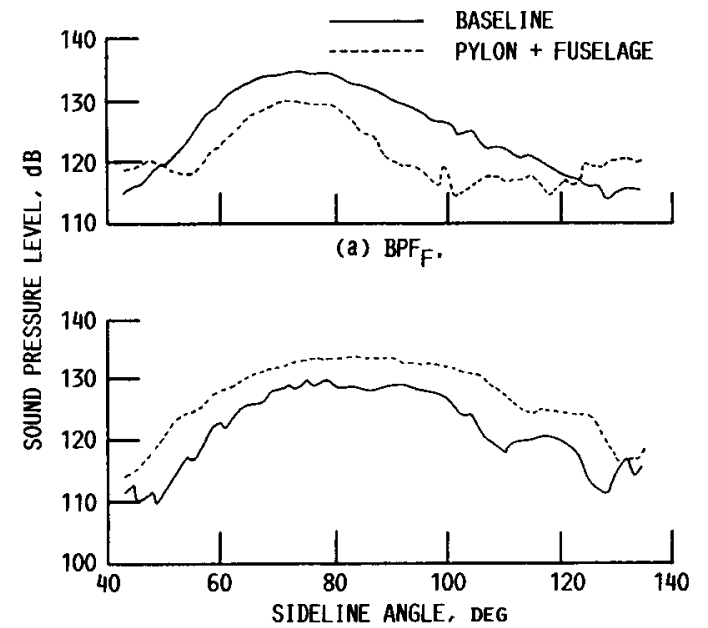

(b) $\mathrm{BPF}_{\mathrm{A}}$.

FIGURE 17. - EFFECT OF PYLON + FUSELAGE ON F7/A3 ROTOR-ALONE TONE SIDELINE DIRECTIVITY, $\Phi=180^{\circ}$. 90\% DESIGN SPEED (61 CM (24 IN.) SIDELINE. $\left.a=0^{0}, M_{\infty}=0.2\right)$.

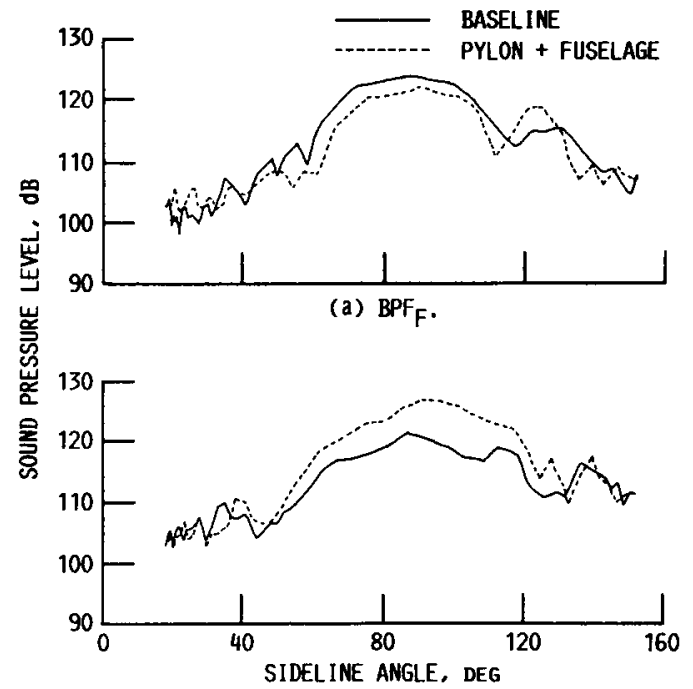

(b) $\mathrm{BPF}_{\mathrm{A}}$.

FIGURE 18. - EFFECT OF PYLON + FUSELAGE ON F7/A3 ROTOR-ALOME TONE SIDELINE DIRECTIVITY, $\Phi=180^{\circ}$. 90X DESIGN SPEED (137 cM (54 IN.) SIDELINE. $\left.\alpha=0^{0}, M_{\infty}=0.2\right)$. 


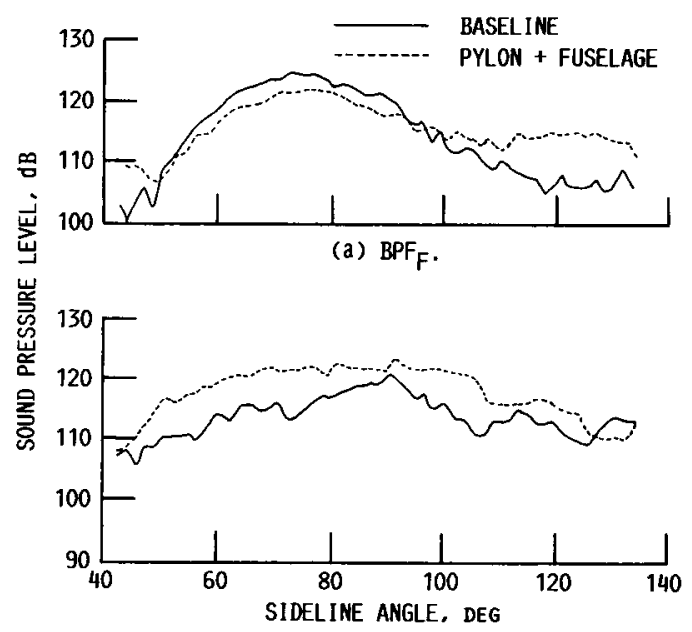

(b) $\mathrm{BPF}_{\mathrm{A}}$.

FIGURE 19. - EFFECT OF PYLON + FUSELAGE ON F7/A3 ROTOR-ALONE TONE SIDELINE DIRECTIVITY, $\Phi=180^{\circ}$ $80 \%$ DESIGN SPEED (61 cM (24 IN.) SIDELINE, $\alpha=0^{0}, M_{\infty}=0.2$ ).

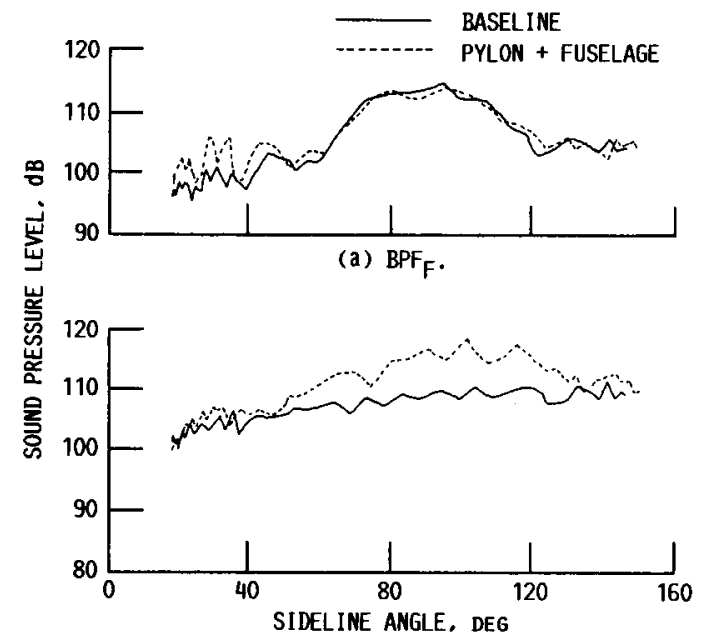

(b) $\mathrm{BPF}_{\mathrm{A}}$.

FIGURE 20. - EFFECT OF PYLON + FUSELAGE ON F7/A3 ROTOR-ALONE TONE SIDELINE DIRECTIVITY. $\Phi=180^{\circ}$. 80X DESIGN SPEED (137 cM (54 IN.) SIDELINE $\left.\alpha=0^{0}, M_{\infty}=0.2\right)$.

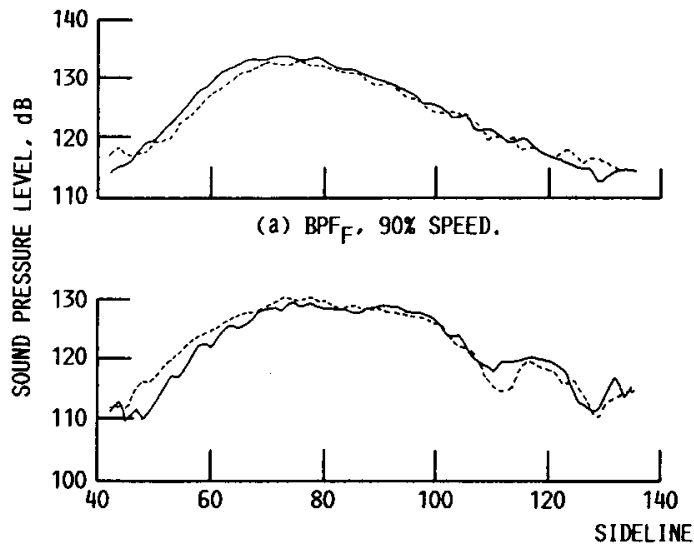

(b) $\mathrm{BPF}_{A^{*}}$ 90\% SPEED.

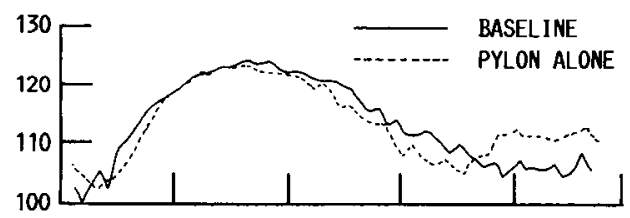

(c) $\mathrm{BPF}_{\mathrm{F}}, 80 \%$ SPEED.

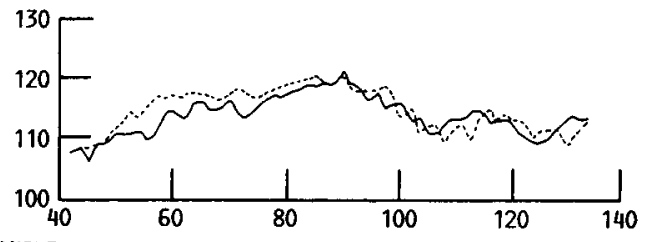

(d) $2 \mathrm{BPF}_{\mathrm{A}}, 80 \%$ SPEED.

FIgURE 21. - EFFECT OF PYLON INSTALLATION ON F7/A3 ROTOR-ALONE TONE SIDELINE DIRECTIVITY, $\$=180^{\circ}$

(61 cM (24 IN.) SIDELINE, $\left.\alpha=0^{0}, M_{\infty}=0.2\right)$. 


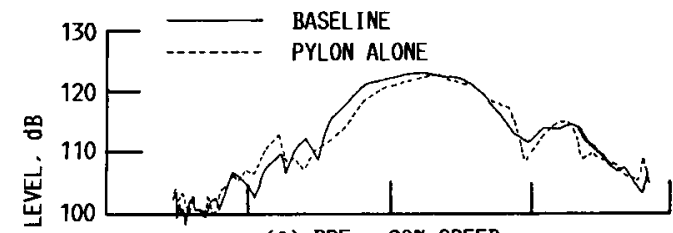

(a) $\mathrm{BPF}_{\mathrm{F}}, 90 \%$ SPEED.

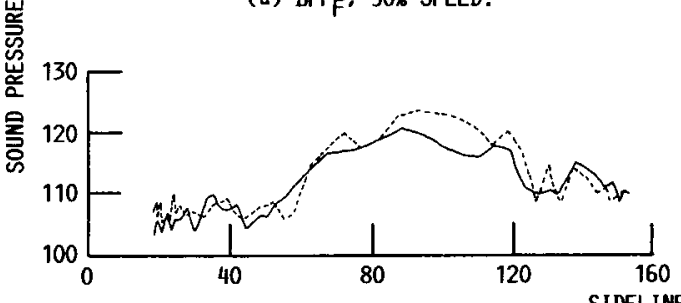

(b) $\mathrm{BPF}_{\mathrm{A}}$, 90\% SPEED.

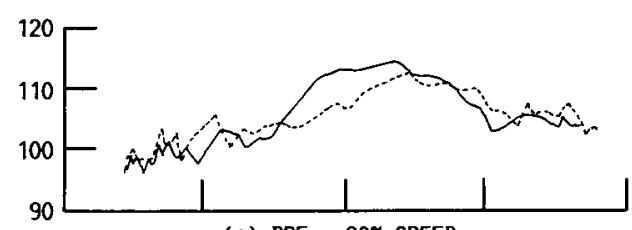

(c) $\mathrm{BPF}_{\mathrm{F}}, 80 \%$ SPEED.

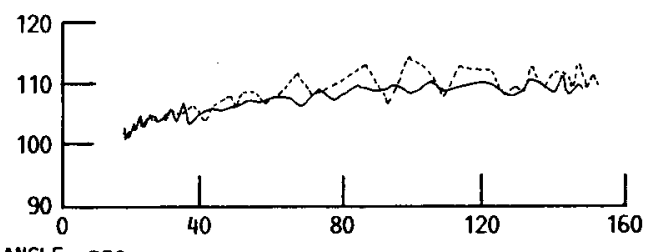

(d) $\mathrm{BPF}_{\mathrm{A}}, 80 \%$ SPEED.

FIGURE 22. - EFFECT OF PYLON INSTALLATION ON F7/A3 ROTOR-ALONE TONE SIDELINE DIRECTIVITY, $\Phi=180^{\circ}$ (137 CM (54 IN.) SIDELINE, $\alpha=0^{0}, M_{\infty}=0.2$ ).

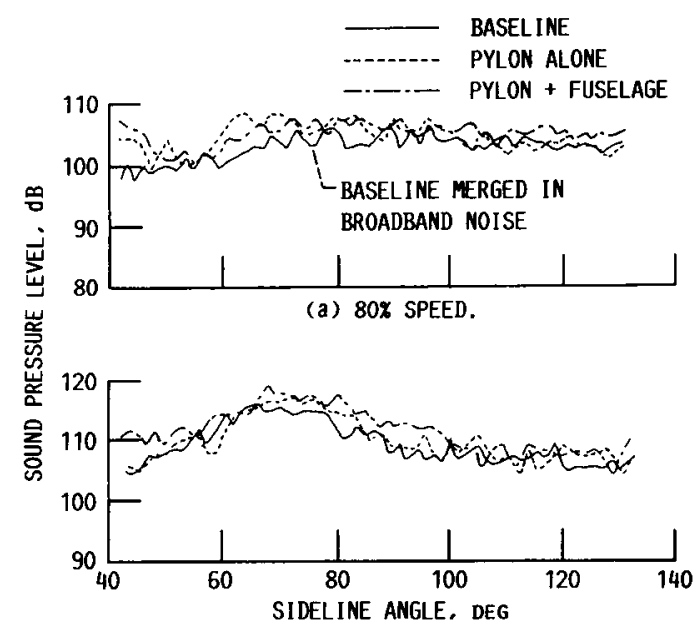

(b) $90 \%$ SPEED.

FIGURE 23. - EFFECT OF INSTALLATION ON F7/A3

2BPF TONE SIDELINE DIRECTIVITY, $\Phi=180^{\circ}$

$\left(61 \mathrm{~cm}\left(24 \mathrm{IN}\right.\right.$.) SIDELINE, $\left.a=0^{\circ}, M_{\infty}=0.2\right)$.

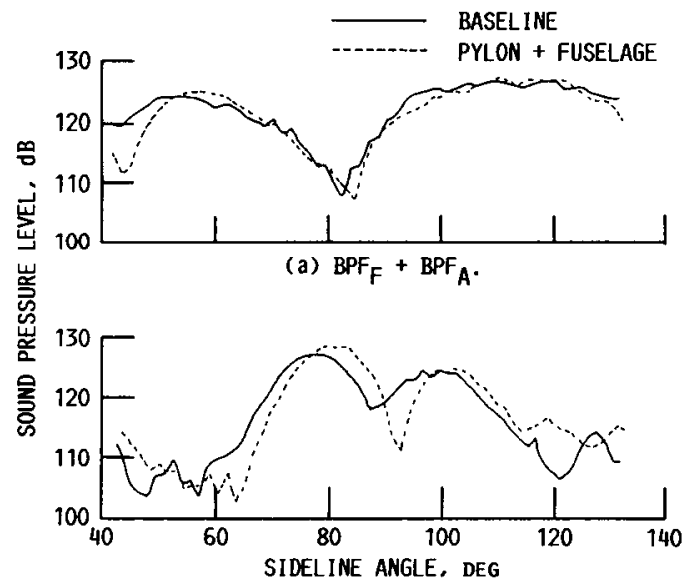

(b) $2 \mathrm{BPF}_{F}+\mathrm{BPF}_{\mathrm{A}}$.

FIGURE 24. - EFFECT OF PYLON + FUSELAGE ON F7/A3 INTERACTION TONE SIDEL INE DIRECTIVITY, $\Phi=180^{\circ}$, 90\% DESIGN SPEED (61 CM (24 IN.) SIDELINE. $a=0^{\circ}, M_{\infty}=0.2$ ).

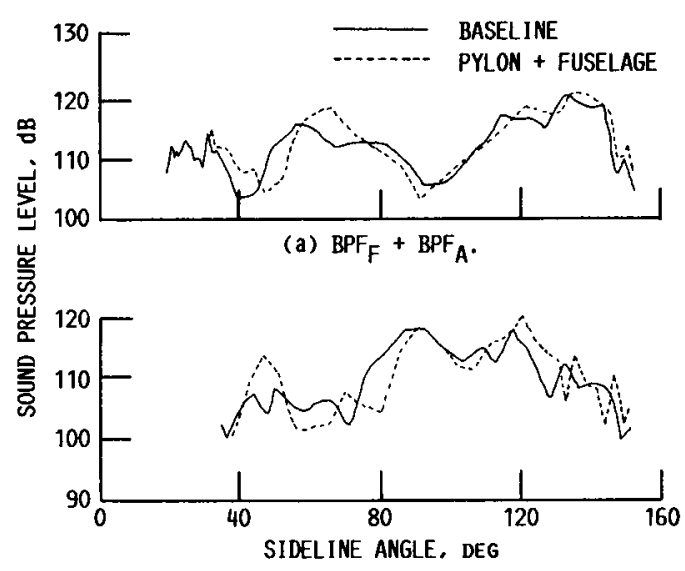

(b) $2 \mathrm{BPF}_{\mathrm{F}}+\mathrm{BPF}_{\mathrm{A}}$.

FIGURE 25. - EFFECT OF PYLON + FUSELAGE ON F7/A3 INTERACTION TONE SIDELINE DIRECTIVITY, $\emptyset=180^{\circ}$. 90\% DESIGN SPEED ( $137 \mathrm{CM}$ (54 IN.) SIDELINE,

$a=0^{0}, M_{\infty}=0.2$ ). 


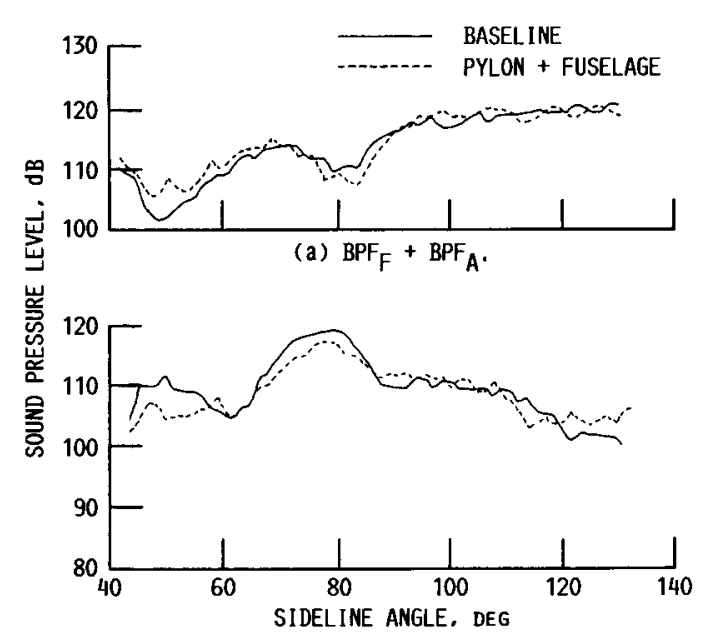

(b) $2 \mathrm{BPF}_{\mathrm{F}}+\mathrm{BPF}_{\mathrm{A}}$.

FIGURE 26. - EFFECT OF PYLON + FUSELAGE ON F7/A3 INTERACTION TONE SIDELINE DIRECTIVITY, $\Phi=180^{\circ}$, 80\% DESIGN SPEED (61 cM (24 IN.) SIDELINE, $\alpha=0^{0} \cdot M_{\infty}=0.2$ ).

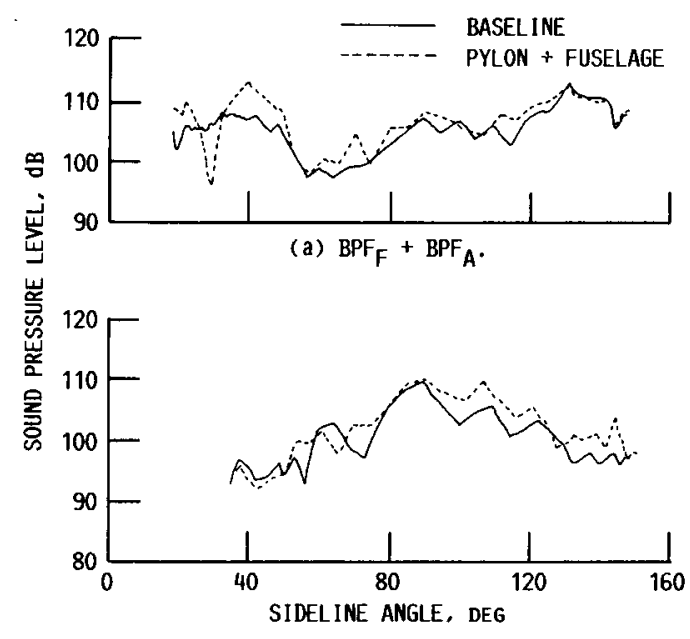

(b) $2 \mathrm{BPF}_{\mathrm{F}}+\mathrm{BPF}_{\mathrm{A}}$.

FIGURE 27. - EFFECT OF PYLON + FUSELAGE ON F7/A3 INTERACTION TONE SIDELINE DIRECTIVITY, $\Phi=180^{\circ}$, 80\% DESIGN SPEED (137 cM (54 IN.) SIDELINE. $\left.a=0^{0}, M_{\infty}=0.2\right)$.

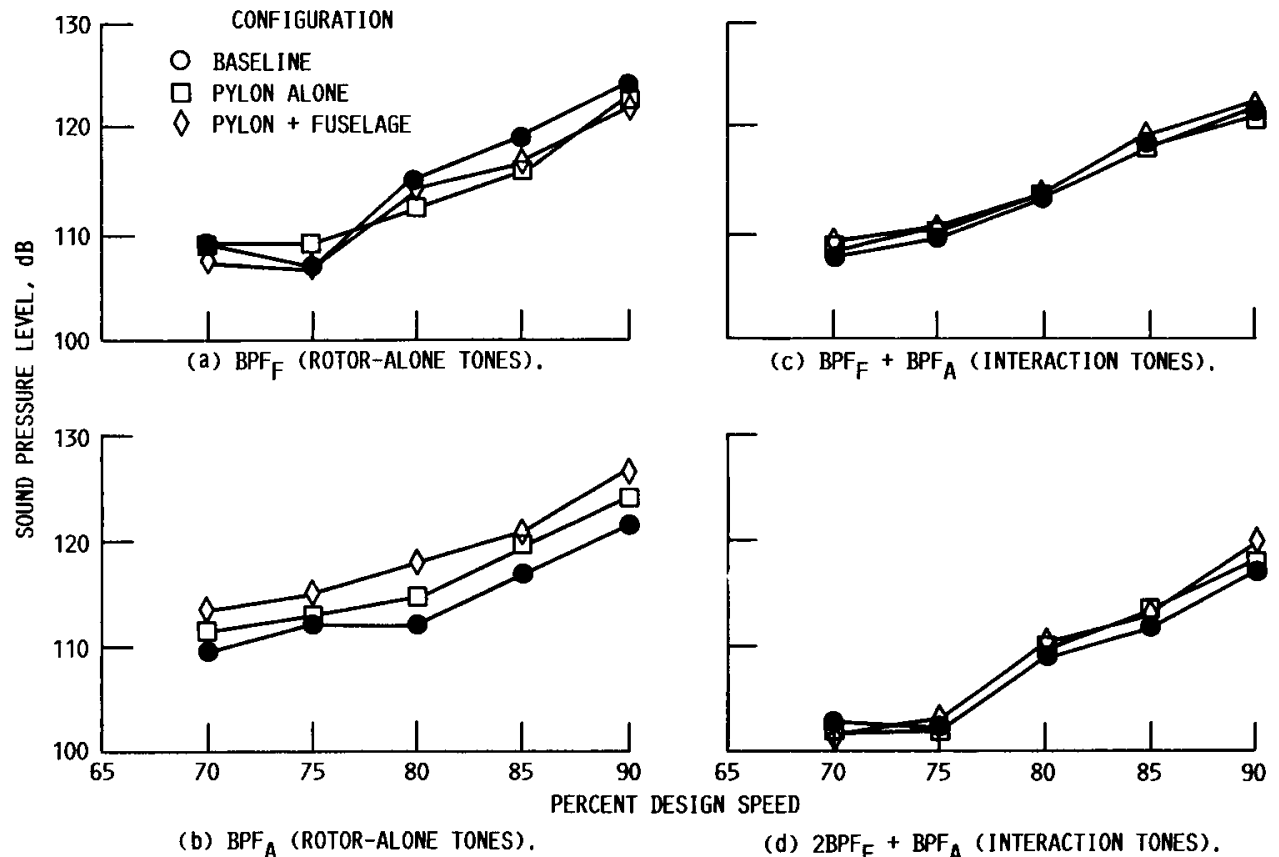

FIGURE 28, - EFFECT OF PYLON + FUSELAGE ON F7/A3 SIDELINE TONE LEVEL, $\Phi=180^{\circ}(137 \mathrm{~cm}$

(54 IN.) SIDELINE, $\left.B_{F} / B_{A}=41.1^{0} / 46.4^{0}, a=0^{0}, M_{\infty}=0.2\right)$. 


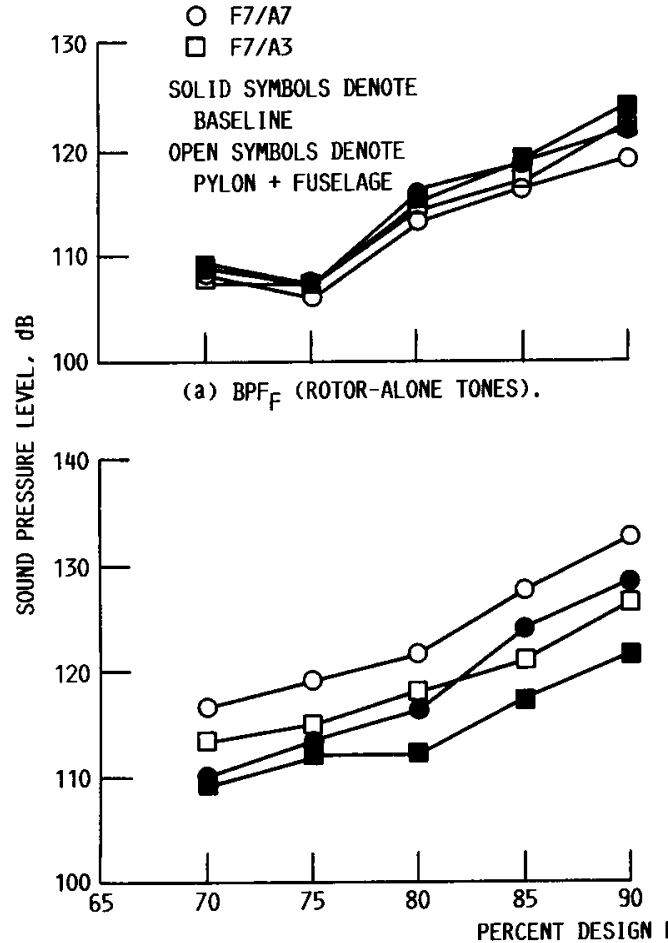

(b) $\mathrm{BPF}_{\mathrm{A}}$ (ROTOR ALONE TONES).

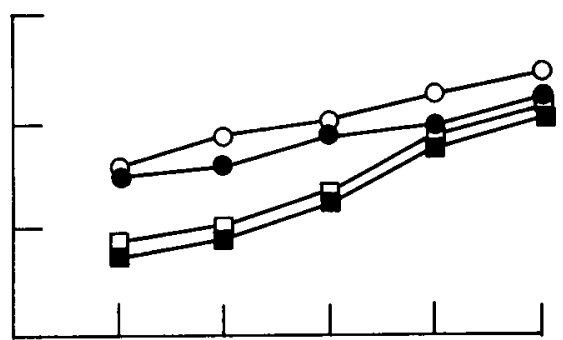

(c) $\mathrm{BPF}_{\mathrm{F}}+\mathrm{BPF}_{\mathrm{A}}$ (INTERACTION TONE).

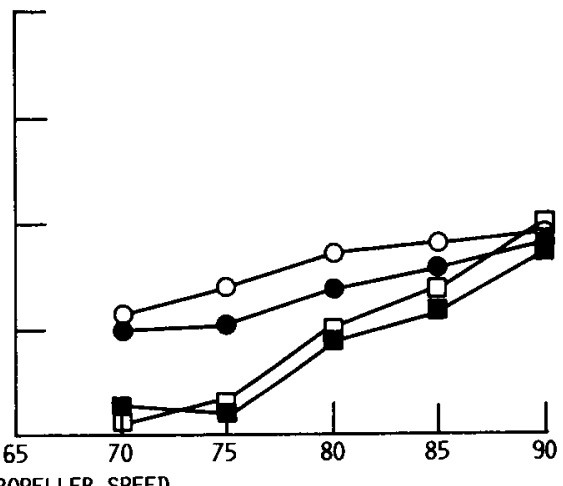

(d) $2 \mathrm{BPF}_{\mathrm{F}}+\mathrm{BPF}_{\mathrm{A}}$ (INTERACTION TONES). CONFIGURATIONS, $\Phi=780^{\circ}$ (137 cM (54 IN.) SIDELINE, $\left.\alpha=0^{\circ}, M_{\infty}=0.2\right)$.

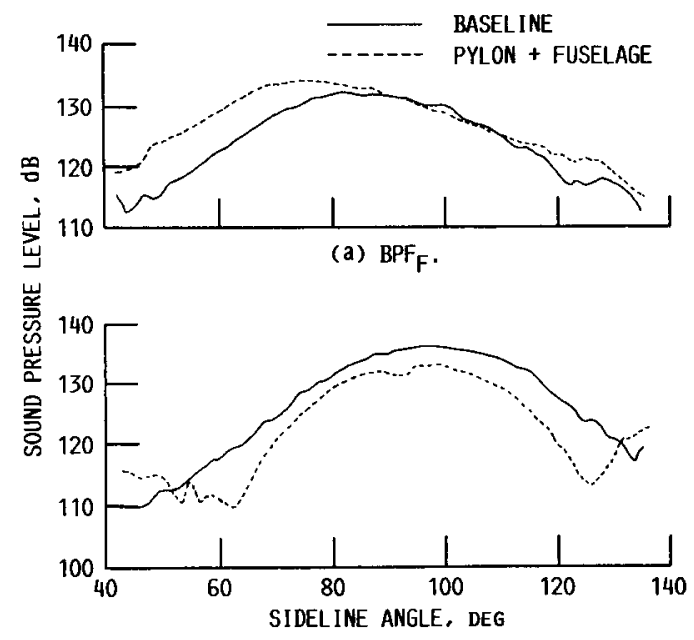

(b) $\mathrm{BPF}_{\mathrm{A}}$.

FIGURE 30. - EFFECT OF PYLON + FUSELAGE ON F7/A7 ROTOR-ALONE TONE SIDELINE DIRECTIVITY, $\Phi=0^{\circ}$, 90\% DESIGN SPEED (61 CM (24 IN.) SIDELINE. $\alpha=0^{\circ}, M_{\infty}=0.2$ ).

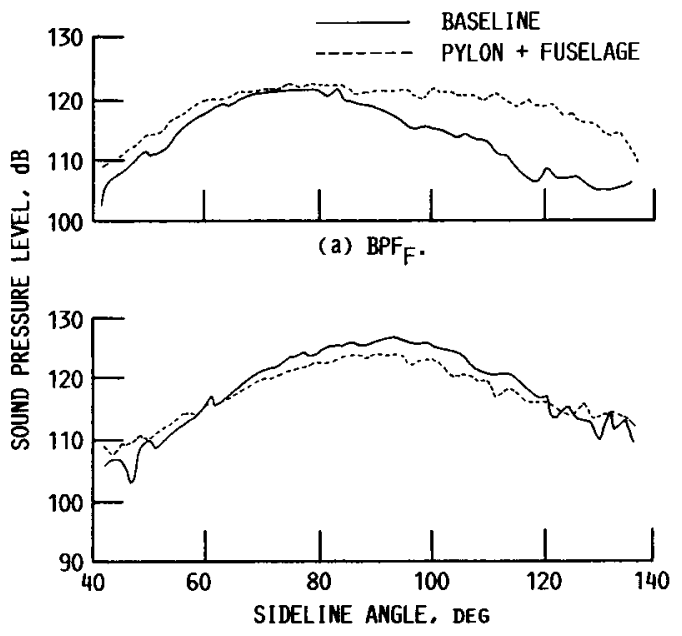

(b) $\mathrm{BPF}_{\mathrm{A}}$.

FIGURE 31 , - EFFECT OF PYLON + FUSELAGE ON F7/A7 ROTOR-AI.ONE TONE SIDELINE DIRECTIVITY, $\Phi=0^{\circ}$. 80\% DESIGN SPEED (61 CM (24 IN.) SIDELINE. $a=0^{0} . m_{\infty}=0.2$ ). 


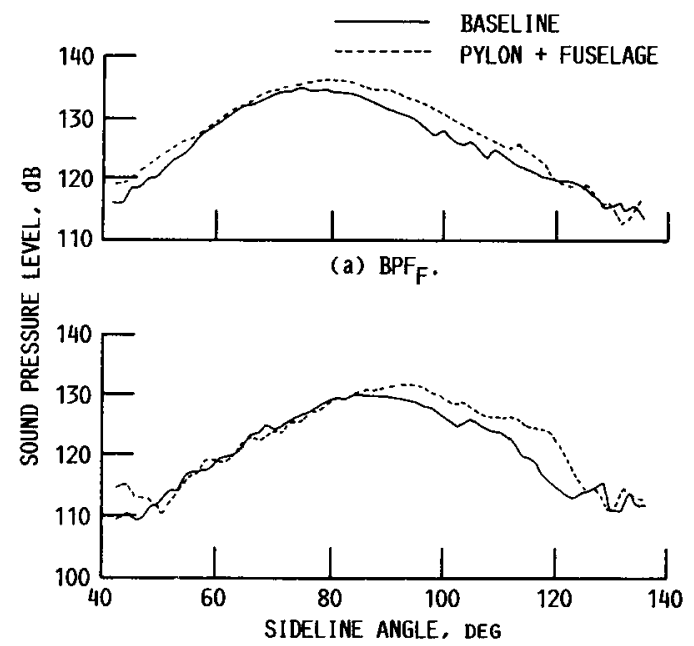

(b) $\mathrm{BPF}_{\mathrm{A}}$.

FIGURE 32. - EFFECT OF PYLON + FUSELAGE ON F7/A3 ROTOR-ALONE TONE SIDELINE DIRECTIVITY, $\phi=0^{\circ}$. 90\% DESIGN SPEED (61 cM (24 IN.) SIDELINE.

$\left.\alpha=0^{\circ}, M_{\infty}=0.2\right)$.

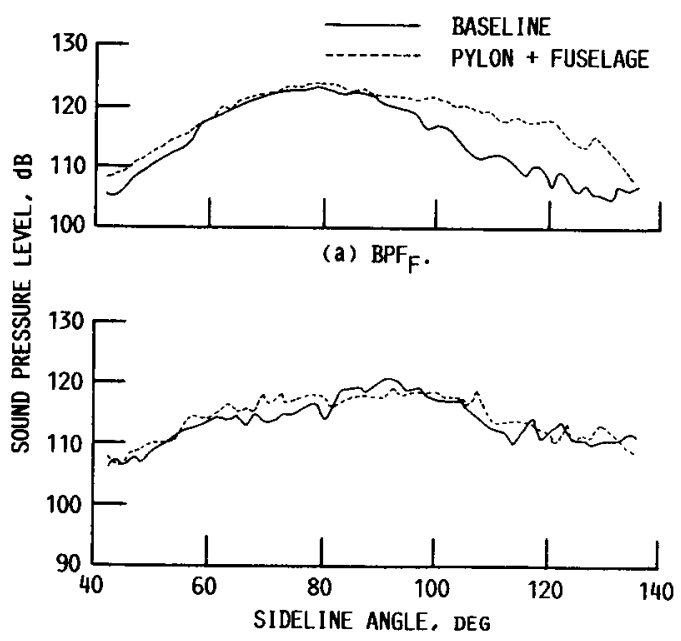

(b) $\mathrm{BPF}_{\mathrm{A}}$.

FIGURE 33. - EFFECT OF PYLON + FUSELAGE ON F7/A3 ROTOR-ALONE TONE SIDELINE DIRECTIVITY, $\Phi=0^{\circ}$ 80\% DESIGN SPEED (61 CM (24 IN.) SIDELINE, $a=0^{0}, M_{\infty}=0.2$ ).

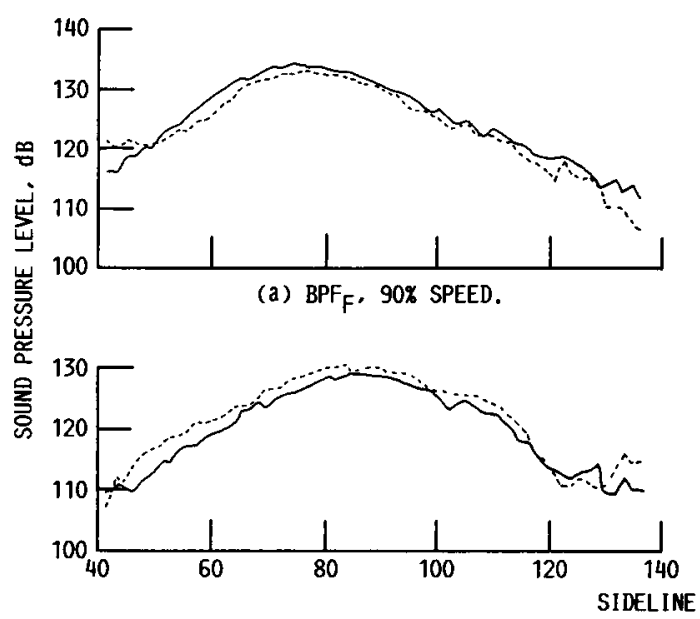

(b) $\mathrm{BPF}_{\mathrm{A}}$. 90\% SPEED.

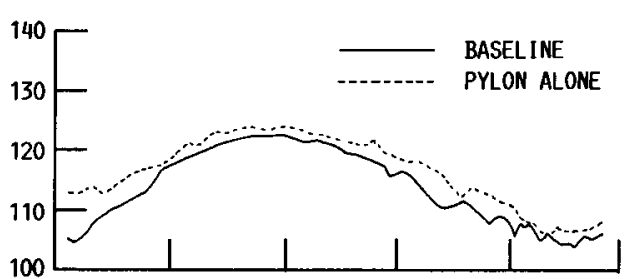

(c) $\mathrm{BPF}_{F}, 80 \%$ SPEED.

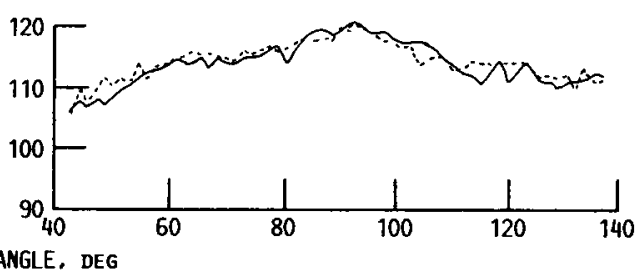

(d) $\mathrm{BPF}_{\mathrm{A}}, 80 \%$ SPEED.

FIGURE 34. - EFFECT OF PYLON INSTALLATION ON F7/A3 ROTOR-ALONE TONE SIDELINE DIRECTIVITY, $\Phi=0^{\circ}$ (61 cM (24 IN.) SIDELIINE, $\left.a=0^{\circ}, M_{\infty}=0.2\right)$. 


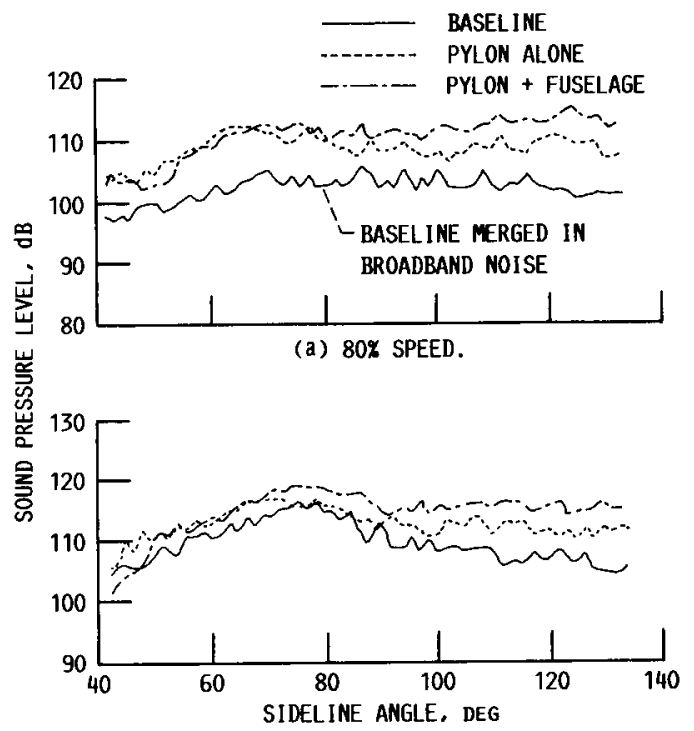

(b) 90\% SPEED.

FIGURE 35. - EFFECT OF INSTALLATION OF F7/A3 2BPF TONE SIDELINE DIRECTIVITY, $\Phi=0^{0}$

(61 cM (24 IN.) SIDELINE, $\left.\alpha=0^{\circ}, M_{\infty}=0.2\right)$.

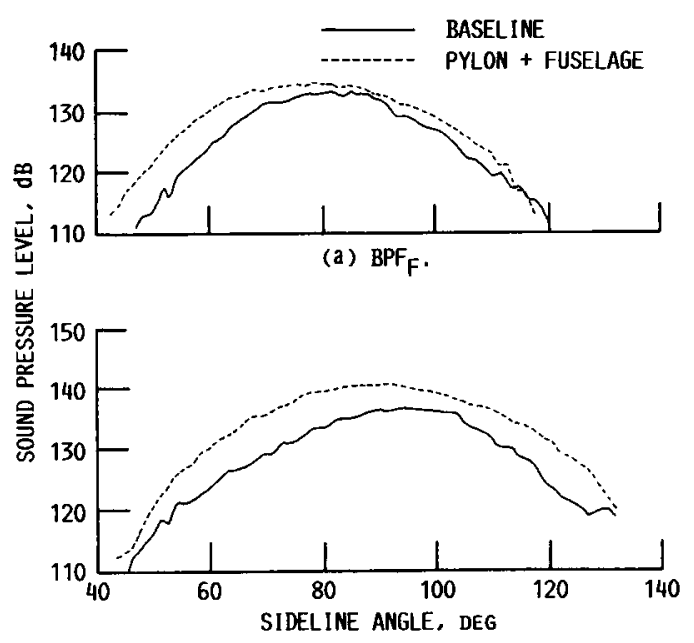

(b) $\mathrm{BPF}_{A}$.

FIGURE 36. - EFFECT OF PYLON + FUSELAGE ON F7/A7 ROTOR-ALONE TONE SIDELINE DIRECTIVITY, $\Phi=90^{\circ}$. 90\% DESIGN SPEED (61 cM (24 IN.) SIDELINE. $a=0^{0}, M_{\infty}=0.2$ ).

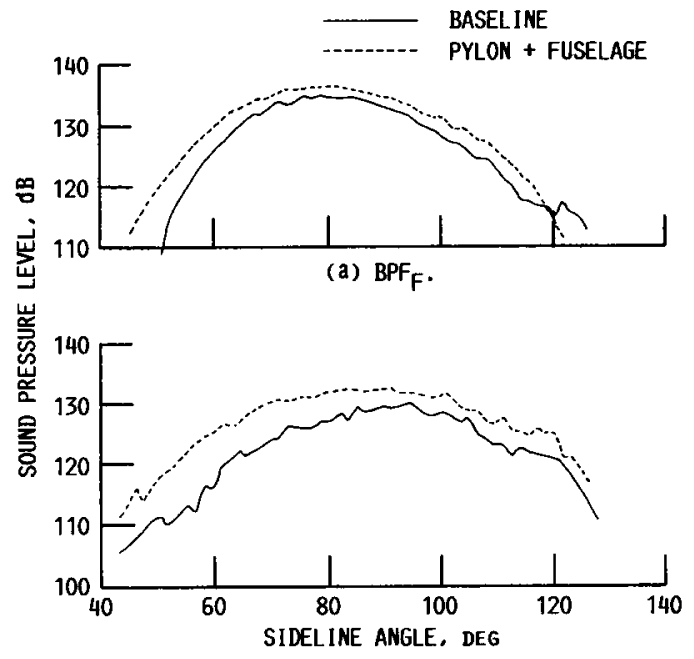

(b) $\mathrm{BPF}_{\mathrm{A}}$.

FIGURE 37. - EFFECT OF PYLON + FUSELAGE ON F7/A3 ROTOR-ALONE TONE SIDELINE DIRECTIVITY, $\Phi=90^{\circ}$, 90\% DESIGN SPEED (61 CM (24 IN.) SIDELINE. $\left.\alpha=0^{0}, M_{\infty}=0.2\right)$. 


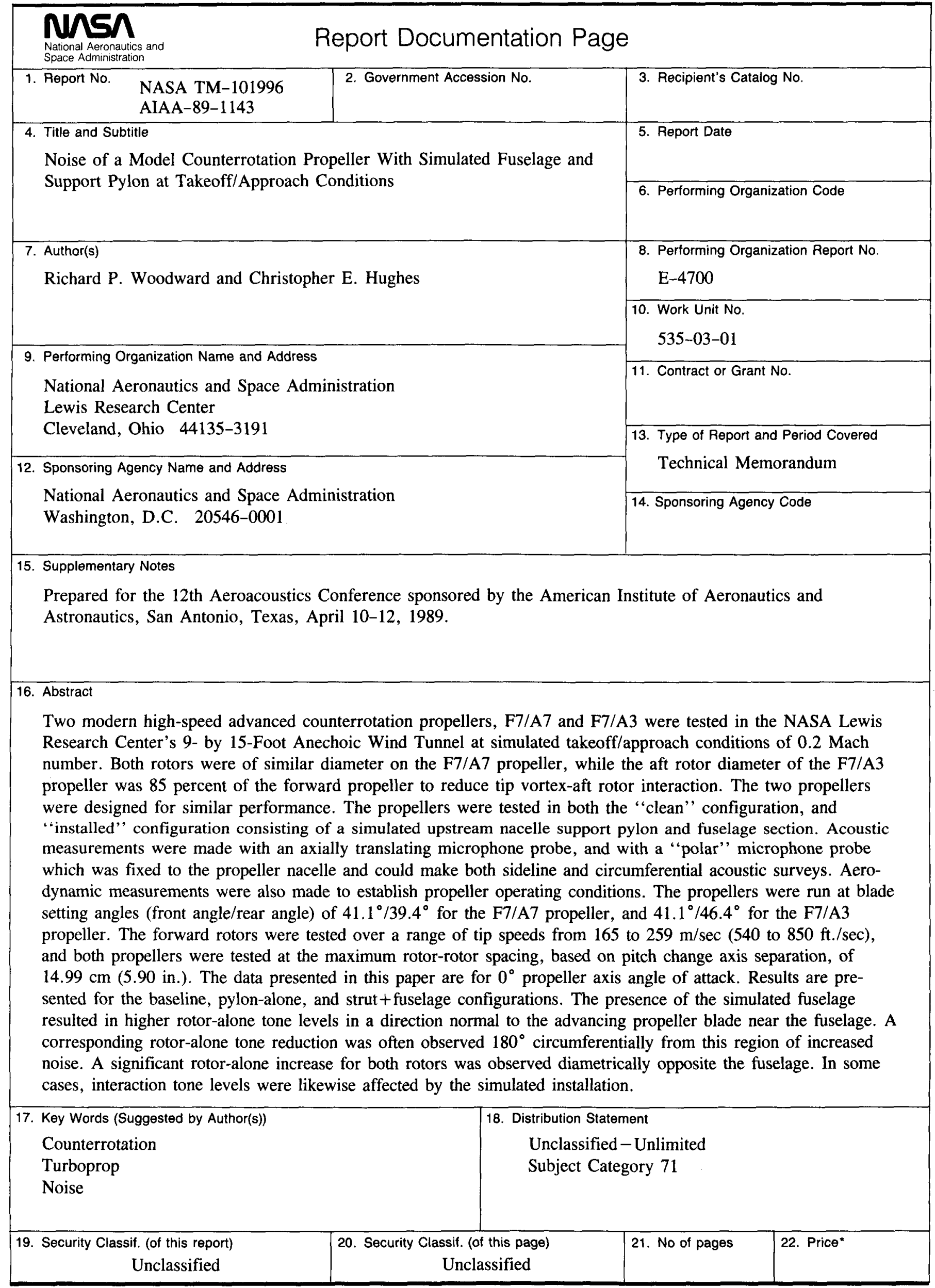

